TI 2011-032/ 1

Tinbergen Institute Discussion Paper

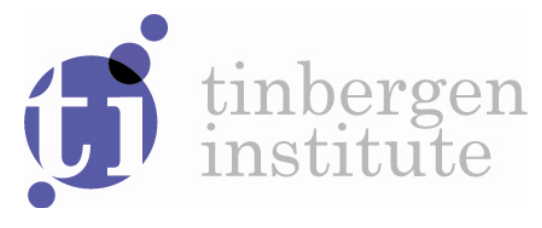

\title{
The Emergence of Social Structure: Employer Information Networks in an Experimental Labor Market
}

Klarita Gërxhanil

Jordi Brandt ${ }^{2}$

Arthur Schram ${ }^{1,3}$

' University of Amsterdam;

2 University Autònoma de Barcelona;

3 Tinbergen Institute. 
Tinbergen Institute is the graduate school and research institute in economics of Erasmus University Rotterdam, the University of Amsterdam and VU University Amsterdam.

More TI discussion papers can be downloaded at http://www.tinbergen.nl

Tinbergen Institute has two locations:

Tinbergen Institute Amsterdam

Gustav Mahlerplein 117

1082 MS Amsterdam

The Netherlands

Tel.: +31(0)205251600

Tinbergen Institute Rotterdam

Burg. Oudlaan 50

3062 PA Rotterdam

The Netherlands

Tel.: +31(0)10 4088900

Fax: +31(0)104089031

Duisenberg school of finance is a collaboration of the Dutch financial sector and universities, with the ambition to support innovative research and offer top quality academic education in core areas of finance.

DSF research papers can be downloaded at: http://www.dsf.nl/

Duisenberg school of finance

Gustav Mahlerplein 117

1082 MS Amsterdam

The Netherlands

Tel.: +31(0)20 5258579 


\title{
The Emergence of Social Structure: Employer Information Networks in an Experimental Labor Market*
}

\author{
Klarita Gërxhani, Jordi Brandts and Arthur Schram
}

January 4, 2011

\begin{abstract}
We use laboratory experiments to investigate how employers develop social structures for sharing information about the trustworthiness of job candidates, when worker opportunism is possible. The experimental data show that substantial information sharing emerges. Two types of information networks are observed. One consists of 'anonymity networks' where information is anonymously and voluntarily provided as a collective good for all employers to use. The other type is a 'reciprocity network' where information sharing is driven by the rewarding of previously given information by the requestor. In both types, the extent of information sharing depends on the costs of providing it. Moreover, information sharing enables employers to recruit trustworthy workers which creates a high quality of trading, benefiting both employer and worker.
\end{abstract}

Keywords: Social structure, Information networks, Recruitment, Experiments

\section{*Acknowledgements}

Financial support by the Spanish Ministerio de Ciencia e Innovación, the Barcelona GSE Research Network Recognition of Research Program and Consolider Ingenio 2010 (CSD2006-00016) and NWO (VENI \#451-04-106) is gratefully acknowledged. We thank seminar participants at the Free University of Brussels and the University of Innsbruck for useful comments. We are also grateful to Jeroen Bruggeman, Vincent Buskens, Andreas Diekmann, Roberto Fernandez, Herb Gintis, Ed Lawler, Luis Miller, Aljaž Ule, and Herman van de Werfhorst, for their detailed comments on an earlier draft of this paper. Remaining errors are ours.

\section{Authors}

\begin{tabular}{|c|c|c|}
\hline Klarita Gërxhani & Jordi Brandts & Arthur Schram \\
\hline Department of Sociology & Department of Business Economics & CREED \\
\hline Amsterdam Centre for Inequality & U. Autònoma de Barcelona and & Amsterdam School of Economics \\
\hline Studies & Institut d'Anàlisi Econòmica, & University of Amsterdam \\
\hline University of Amsterdam & CSIC & Roetersstraat 11 \\
\hline Oudezijds Achterburgwal 185 & Campus UAB & 1018 WB Amsterdam \\
\hline 1012 DK Amsterdam & 08193 Bellaterra (Barcelona) & The Netherlands \\
\hline the Netherlands & Spain & \\
\hline phone $+31-20-525.4113$ & phone $+34-93-580.6612$ & phone $+31-20-525.4293$ \\
\hline fax $+31-20-525.3010$ & fax $+34-93-580.1452$ & fax $+31-20-525.5283$ \\
\hline k.gerxhani@uva.nl & Jordi.Brandts@uab.es & Schram@uva.nl \\
\hline
\end{tabular}




\section{INTRODUCTION}

Understanding the emergence of social structure is a central issue in sociology (Parsons 1937; Cook and Emerson 1978; Granovetter 1985; Coleman 1986; Kollock 1994, Lawler and Yoon 1996). By a social structure we mean any configuration of social relations (Granovetter 1985). The study of social structure is an area in which sociology has significantly contributed to the social sciences. In spite of an increasing interest over the past decade (Brown et al. 2004; Fehr and Gintis 2007; Karlan et al. 2009; Bandiera et al. 2009, 2010) mainstream economists have typically paid less attention to it. Though many economists have now come to recognize that a full understanding of human behavior is impossible without taking the social context into account, ${ }^{1}$ its dynamics and the way this affects economic systems such as markets has received much less attention.

The recent award of the 2009 economics Nobel prize to Oliver Williamson can be seen as a recognition of the importance of the structure involving traders in hierarchical firms vis-àvis organized markets. Williamson $(1975,1985)$ has argued that markets and hierarchical firms represent alternative governance structures which differ in their approaches to resolving conflicts of interest. In his seminal paper, Granovetter (1985) gives credit to Williamson's recognition of structure but emphasizes the lack of focus on the social relations and their dynamics in which both markets and firms are embedded. Uzzi (1997) also stresses the need to examine social structure, especially when considering inter-employer relationships.

In this paper, we explore how social structure influences decisions in a domain that most economists consider to be central to their discipline: the labor market. We examine the emergence of a specific social structure, to wit networks for information sharing between employers when hiring new workers. The structure of the social relations between employers is studied in detail, as is how these affect the relation between employers and workers on the labor market. Our study illustrates some of the ways in which material incentives and emerging social relations interact and may therefore be seen as an attempt to contribute to bridging the gap between sociology and economics (Gintis 2009).

Information sharing networks are prominent in a number of areas of social and economic life in which there is uncertainty about certain characteristics of some of the relevant agents (Rees 1966; Raub and Weesie 1990). Think, for instance, of the sharing of information about the reliability of borrowers in the financial sector (Brown and Zehnder 2005; Karlan et al.

\footnotetext{
${ }^{1}$ There is some indication of an increasing influence of sociology in the economics literature. For example, the number of citations to the AJS and ASR in the 2009 volume of the Quarterly Journal of Economics was 8, after averaging 3.6 in 1997-2008.
} 
2009); about the quality of applicants to higher education institutions; or about the appropriateness of particular individuals as marriage partners. Our focus is on the role of employers' information networks in the recruitment process for new personnel. ${ }^{2}$ Two (related) examples serve to show how information may be shared in this process. First, an employer looking to hire a new worker may receive information from other employers in her network about suitable candidates that have worked for them in the past. Second, these other employers may write recommendation letters providing specific information about these former workers. ${ }^{3}$ For information exchange within employers' networks, we are not thinking of standardized recommendation letters for multiple use (as in many types of job markets) but of more direct recommendations from one employer to another (perhaps through personal correspondence, or otherwise in personal contact when playing golf or at a charity gathering, for example).

In a stylized representation of the hiring process employers can be considered to recruit workers through two broad channels: on the one hand the 'official' ('formal') channel which resembles a centralized market and on the other informal networks (Rees 1966; Montgomery 1991; Marsden 2001; Russo et al. 2001). Information sharing is more likely to play a role in the latter channel. In a centralized market, numerous employers and workers interact and a substantial part of the information about offers and trades is disseminated to all market participants. In many countries, public or private employment agencies provide the services of such centralized exchanges; some of the internet job-matching sites have similar characteristics. In informal networks contacts between employers and workers are made in a much more decentralized way. This channel is widely used and for some types of jobs, it generates the most job matches (Granovetter 1974; Corcoran et al. 1980; Holzer 1987; Montgomery 1991; Flap and Boxman 2001). It is important to note that social relations may play an important role in both channels, though the type of relations and their effect may differ.

The choice between recruitment channels involves a trade-off between the centralized market's possibility of establishing contacts with a large number of workers and the network's more accurate information about the prospective workers (Granovetter 1973). When hiring new employees, employers are often quite uncertain about particular

\footnotetext{
${ }^{2}$ The information networks that we study are networks in the sense of Podolny and Page (1998) of a collection of actors that pursue repeated, enduring exchange relations with one another without a legitimate organizational authority to arbitrate and resolve disputes that may arise during the exchange. Many business groups and strategic alliances are instances of such networks without a formal arbiter.

${ }^{3}$ Letters for former employees are the most obvious example. One may also think of recommendation letters for current employees, but then the interests of the current employer (who may want to keep the worker) need to be taken into account. We thank Roberto Fernandez for pointing this out to us.
} 
characteristics of prospective candidates. Recruiting involves, among other things, finding ways to reduce this uncertainty. Whereas some characteristics may be derived from information provided directly by a candidate (her education may be informative about her human capital or productivity, for example) other characteristics may be harder to discover. We will focus on one such characteristic in particular, to wit, the candidate's trustworthiness in situations where worker opportunism is possible.

In many occupations workers have considerable discretion about their performance at a job (e.g., Williamson 1985; Milgrom 1988; Baker 1992; Goldthorpe 2000; Eguchi 2005). As a result, monitoring is difficult and costly, making the acquisition of information about a candidate's trustworthiness a crucial element in the recruitment process. If so, the performance history of prospective workers may be relevant information at the time of the recruitment decision. This information pertains directly to actual work-related behavior in the past and therefore it may indicate how trustworthy a worker may be expected to be in the present. "Better than the statement that someone is known to be reliable is information from a trusted informant that he has dealt with that individual and found him so..." (Granovetter 1985:490). Other employers that have previously employed the worker may be seen as trusted informants in the Granovetter sense.

We have previously shown that the availability of information about a candidate's trustworthiness strongly affects the channels through which employers recruit (Schram et al. 2010). This information allows employers to use the informal channel to hire more trustworthy workers. A fundamental limitation of the set-up in our previous paper is that information was exogenously given to all employers. The central focus of the present study is the question of how and under what circumstances social relations amongst employers facilitate the dissemination of such information. In addition we establish the effects of these social relations on the choice of recruitment channel and the trading quality that results from this. This is important because the emergence of information sharing between employers is not a priori obvious (as noted in a more general setting by Buskens et al. 2010). While each individual employer is interested in obtaining information from others, none has a direct material incentive in providing it; sometimes it may even be costly to do so (Marsden 2001). We argue here that the existence of pro-social motivations, the influence of reputation and the interaction of these two forces may lead to the emergence of stable social relations between employers that give rise to information networks.

There are no theoretical models that suggest to the analyst what behavior to expect in a study of social exchange in an environment like the one used here. The empirical method we 
apply is that of laboratory experimentation. The laboratory provides an ideal environment to study social structures because one can observe with precision their emergence and the underlying mechanisms. The two main virtues of laboratory experiments are control and replicability. Causal knowledge requires controlled variation (Falk and Heckman 2009) and the laboratory allows for tight control over the environment in which interaction takes place. At the same time, it is possible to generate sufficient data in a simple way.

Our study combines insights and methods from sociology and economics. Fehr and Gintis (2007) present a strong argument for the need for such interaction. They discuss some of the experimental and analytical foundations of human motivation and social cooperation. Among the issues to be studied they refer to the micro-foundations of emergent patterns of social interactions. Our experiment explicitly allows for such a micro-macro perspective (as do Corten and Buskens 2010, for example). We vary the properties of information sharing between employers and analyze the effects of these variations on macro-level properties such as the resulting network. Since we can observe all individual decisions (for example, whether or not to give information) we can study in detail how behavior at the micro-level leads to macro-level outcomes.

In what follows, we first present more of the background underlying our study. We then present our method, discussing the experimental design, the participants in the experiment and the procedures used. In the last three sections we present our results, a discussion of their implications and the conclusions.

\section{STATE-OF-THE-ART}

Various studies in sociology and economics are relevant for our analysis. ${ }^{4}$ For example, some sociological papers investigate the endogenous emergence of networks in the laboratory. ${ }^{5}$ First, Corten and Buskens (2010) use simulations and experiments to analyze how networks and behavior in a coordination game co-evolve. They find that the extent of coordination depends both on characteristics of the game and on the density of the network. More

\footnotetext{
${ }^{4}$ We discuss here the literature most closely related to the endogenous formation of information networks in recruitment. Other literature is more indirectly related. First, there are many studies on recruitment strategies (see Schram et al. 2010 for an overview). Second, the rich literature on indirect reciprocity (see Seinen and Schram 2006 or Ule et al. 2009 for references) is relevant for our analysis of worker reputations, but typically involves very different settings. Third, for an example of how firms may form networks with other firms in order to exchange information on other issues than recruitment, see Cassar et al. (2009). Finally, for more general and recent studies of experimental sociology, see Willer and Walker (2007) and Webster and Sell (2007). We consider the discussion of these literatures to be beyond the scope of this paper.

${ }^{5}$ For related work in the economics literature see Callander and Plott (2005), Corbae and Duffy (2008), Falk and Kosfeld (2003) and Goeree et al. (2008). These all follow protocols for network formation that are similar to those in the papers discussed here.
} 
generally, Burger and Buskens (2009) show experimentally that actors endogenously form networks to reach better positions in various contexts. They also observe that efficient networks and networks in which everyone is equally well off both occur more often than predicted by theory. Finally, Brauna and Gautschi (2006) show that network positions (as well as relational features) are important determinants of outcomes (profit splits) in bargaining games. All of these studies serve as examples of how networks are formed in the laboratory and how participating in such networks may be beneficial. In this general sense, our conclusions will confirm these previous results. The approach followed here differs from these previous studies in important ways, however. First of all, the typical procedure in the experimental analysis of networks has been to explicitly ask subjects if they want to be linked to one or more others. If not, there is a fall-back option (usually the subject no longer actively participates and receives an outside -fixed- payoff instead). In our setup, there is no explicit decision to link to someone else. Instead, subjects decide whether or not to provide information. Ex post, we can study whether this has led to network structures. A second difference is that we do not use a fall-back option. In the environment we are interested in, employers want to hire a worker. If they do not give (or receive) information via a network, they still want to hire. In other words, the set of options they choose from is not affected by whether or not they are linked to others. In this way, our setup more closely resembles the way in which informal networks are formed outside of the laboratory. It is uncommon for employers to be explicitly asked to join an 'old boys' network', for example.

Another difference is that in the networks considered in these previous studies, there are no issues of trustworthiness, while this is a central focus of our research. In a different setting, Kollock (1994) provides a seminal experimental sociological study on the importance of trustworthiness in trading relations. He analyzes how the establishment of fixed trading partnerships (e.g., between an employer and employee) depends on the uncertainty about the quality of the good to be traded. ${ }^{6}$ Among the future directions for social exchange theory he includes "the need to investigate the emergence of social structure as well as its effects, and the relevance of reputation (and other factors related to the signaling and collection of information) to exchange process" (Kollock 1994:342). Our study aims to address precisely this need.

In our setup, the information shared in a network of employers may affect the relation between an employer and a worker. Some previous experimental studies have dealt directly

\footnotetext{
${ }^{6}$ Brown et al. (2004) are an example of economists interested in very similar issues.
} 
with how behavior in a social relation is affected by information provided by others. ${ }^{7}$ For example, Buskens et al. (2010) have two trustors play a standard trust game sequentially with one trustee, with this sequence taking place fifteen consecutive times. ${ }^{8}$ In one situation each trustor only has information about the own interaction (an example of 'dyadic embeddedness'), while in the other situation information is also given about the interaction between the other trustor and the trustee (yielding 'network embeddedness'). Both types of embeddedness are exogenously imposed. The authors conclude that both dyadic and network embeddedness affect behavior. Trustees become more trustworthy in reaction to the possibility that trustors may sanction them based on information obtained through their own experiences or the 'network'. In turn, this increased trustworthiness increases trust. This work is important in that it shows how information from a network may affect its relations. It is very different from our research, however. Most importantly, we study the endogenous formation of networks for information exchange. Moreover, by design we will exclude the possibility of recognition of a worker by an employer. Hence, there are no repeated game effects between the two (and no possibility of direct reciprocity of previous choices). This allows us to focus directly on the effects of network information.

To the best of our knowledge, there are no previous experiments studying the relationship between networks and markets in the way we do. A theoretical study by Bowles and Gintis (2004) is relevant, however. They investigate the interplay between ethnic networks and an anonymous market. The cultural affinity of ethnic networks can support enforcement of prosocial behavior among members by reducing information costs, while the anonymous market has the virtue of offering unrestricted trading opportunities. The authors apply a general equilibrium model in which the size of the anonymous market and the size of parochial networks are determined endogenously. Exchanges between group members happen only once. These two features are common with our research design. There is one crucial difference, which is that in their model network members automatically have access to a common pool of information, whereas our experimental set-up is designed precisely to study the process by which such a common pool is endogenously created.

Aside from the experimental and theoretical literature, there is also a rich empirical literature in sociology studying the use of networks in the recruitment process. Marsden (2001) points to the information benefits of employers' network contacts. These benefits are

\footnotetext{
${ }^{7}$ More generally, Buskens and Raub (2010) give an overview of experimental and other research on the effects of embeddesness on trust in social dilemmas.

${ }^{8}$ In a trust game, a trustor may transfer money to a trustee. The experimenter adds to the amount transferred and then the trustee decides whether or not to transfer any money back to the trustor.
} 
particularly high for jobs where performance and skills are difficult to observe. This provides important input for our experimental approach. Inter alia, laboratory control will allow us to derive causal inferences about the relationship between such networks and their consequences for recruitment. Fernandez et al. (2000) and Fernandez and Castilla (2001) present in-depth studies of the role of social networks in the hiring of new phone center workers via employees' referrals. They study the benefits to the firm by hiring through employees' networks, distinguishing between the 'richer pool', the 'better match' and the 'social enrichment' hypotheses. ${ }^{9}$ The results show evidence in support of the 'richer pool' hypothesis: the pool of referred applicants is more qualified and more readily hirable than non-referral applicants. As a consequence, an important mechanism by which employers can benefit from using their employees' social networks is through lower screening costs. Erickson (2001) adds to this by observing that for many upper-level jobs employers consider employees' networks as a job qualification per se. As a consequence, they prefer to hire people with larger social networks. In general terms, such results are related to our study, because of the focus on the socially embedded nature of the recruitment process. A substantial difference is that while most of these authors look at employers' benefits from utilizing employees' social ties, we focus on the social network between employers themselves.

We will also add to this literature by distinguishing between two properties of information networks that may influence the way information is shared. The first property deemed to be important is the cost of information exchange. Raub and Weesie (1990:648) argue that such costs should be included in the analysis, because they may limit the effectiveness of stable employer information networks even in the presence of common interests. To accommodate this possibility, our design will vary the information transmission cost. When there are such costs, creating and maintaining networks is also costly (Marsden 2001). The second property deemed to be important is whether, in the process of information sharing, identities are known or not. This is because any kind of reputation formation (e.g., Raub and Weesie 1990) requires that one can identify other individuals. Our design will carefully distinguish between a situation in which an employer who requests information can identify those other employers who decide to transfer information and those that do not (and vice versa, the employer who asks for information can be identified) and a situation where such identification is impossible. This distinction will allow us to separate the impact on the formation of social networks of on

\footnotetext{
${ }^{9}$ In related empirical studies, Fernandez and Sosa (2005) study gender segregation effects and Fernandez and Fernandez-Mateo (2006) study race issues in the recruitment process through networks.
} 
the one hand reputation building and reciprocity and on the other hand pro-social behavior aimed at anonymous others. The former is impossible without identification.

More specifically, identifiability may be important because closure (a.k.a. 'density') of networks (Coleman 1988) is only possible with identification. Closure measures the extent to which any two agents connected in a network both have connections to the same third parties (Burt 2005; Karlan et al. 2009). Coleman points out that in a closed network reputation can arise and sanctions are possible. As a consequence, if in creating information networks employers are guided by self-interest, then relatively closed networks will be most effective and therefore identification will positively affect the probability that successful information networks will emerge. On the other hand, if social embeddedness is the main generator of information sharing (Granovetter 1985; Uzzi 1997), then calculative risk and monitoring systems may be less important and closure is immaterial. As argued in Lawler and Yoon (1996), the commitment to a social network would in this case be driven by a moral obligation to contribute to a collective good. ${ }^{10}$ In this line of argument, identification is not necessary for the emergence of information networks and may even be harmful (Granovetter 1985). The distinction based on the identification (or not) of others within a network, will thus allow us to examine which of the paradigms -Coleman versus Granovetter- is at play.

\section{METHOD}

The labor market environment we study is one with more workers than employers, i.e., of excess supply for workers. ${ }^{11}$ This is empirically the more relevant case to study because while workers have a market disadvantage in that not all of them can be employed, they have an advantage within the employment relation, because they can independently determine their performance after the wage has been established. This creates a certain power balance in the social relation between employers and workers, which is precisely what makes it an interesting environment to study.

\section{Design}

In the laboratory, the experimental situation is presented in terms of a market in which an abstract good is traded between buyers and sellers. However, given our focus on recruitment

\footnotetext{
${ }^{10}$ Note that such a moral obligation need not be unconditional. For example, it may involve an obligation to contribute, if enough other people are doing so (e.g., Diekmann and Lindenberg 2001).

${ }^{11}$ This has received most attention in previous literature. Kollock (1994) also considers this as an important environment to study. See Schram et al. (2010) and Brandts and Charness (2004) for studies that also consider the case of excess demand for workers, i.e., the case of more employers than workers.
} 
in the labor market, we will henceforth maintain the reference to 'employers' and 'workers' instead of buyers and sellers, respectively.

In line with the discussion in the previous section, our design consists of four separate experimental treatments, varying along two dimensions. The first dimension consists in whether or not employers can identify each other when sharing information. ${ }^{12}$ The second dimension along which our treatments differ is in whether information is costless or costly. We ran a full $2 \times 2$ combinatorial design. It is a between-subject design meaning that each participant takes part in only one group of one of the treatments. Table 1 summarizes our design and gives the number of experimental groups we ran per treatment cell.

[Table 1 here]

\section{Participants}

The experiment was run in the spring of 2009 at the CREED laboratory of the University of Amsterdam. 234 participants were recruited from CREED's subject pool. This consists of around 2000 individuals who have voluntarily registered. Almost all of these are undergraduate students at the University of Amsterdam. All received an invitation to sign up and participation was on a first-come, first-serve basis. Participants took part in nine sessions, with a total of 26 groups (see table 1). In each group, four participants were employers and five were workers and each participant had the constant role of either an employer or of a worker. Sessions lasted approximately 135 minutes, and participant earnings were performance based, with an average of $€ 29.75$ (including a $€ 7$ show-up fee).

\section{Procedures}

The participants in any session of the experiment interact in 30 rounds, preceded by three practice rounds. The same four employers and five workers interact anonymously in a group throughout the 30 rounds. A labor contract always involves one employer and one worker, so that each trader (employer or worker) can be involved in at most one contract per round, and there can be at most four contracts per group and round. The 30 rounds are split into 10 initial rounds and the 20 subsequent rounds which constitute the central part of our sessions. We first present the workings of the central 20 rounds. ${ }^{13}$

\footnotetext{
${ }^{12}$ In the experiment, participants take part anonymously. As explained below identifiability is based on fixed participant codes and makes it possible to keep track of another participant's decisions over time. Of course, non-identifiability is not intended to describe actual practice in social relations between employers. Instead, it provides a benchmark that allows us to isolate the role of identification in social relations.

${ }^{13}$ In our study each group involves nine participants. For a study involving larger groups (but in a different context) see Brandts et al. (2010).
} 
The description of the central part of our treatments involves two inter-linked parts: the description of how agreements between employers and workers are reached and the description of how information is disseminated through employers' networks. In these 20 rounds recruitment can take place though two channels: a centralized market or bilateral (private) negotiations. Employers and workers can choose which they would like to enter. In a way to be described below, either type of interaction between employer and worker may yield a labor contract at an agreed upon wage.

After all trading activity has ended, each worker involved in a labor contract chooses the 'effort' she is willing to give. The two possible effort levels are 'high' $(e=1)$ and 'low' $(e=0)$. This affects the monetary payoffs of employers and workers in the following way. An employer's payoff $\left(\pi_{f}\right)$ is equal to the revenue resulting from the worker's effort level, $r(e)$ minus the wage paid, with $r(1)=50$ and $r(0)=10 .{ }^{14}$ A worker's payoff $\left(\pi_{l}\right)$ is equal to the wage received, $w$, minus the cost of effort $c(e)$, with $c(1)=20$ and $c(0)=0$. Note that high effort maximizes the joint earnings of the worker and employer, which is 30 francs (50-20) for high effort and 10 francs (10-0) in case low effort is chosen. The wage determines how these joint earnings are divided between the two. Summarizing:

$$
\begin{aligned}
& \pi_{f}=r(e)-w \\
& \pi_{l}=w-c(e) .
\end{aligned}
$$

Workers and employers that are not involved in any labor contract earn zero in that round.

The choice between channels works as follows. At the beginning of each of the 20 rounds each employer can express a wish to negotiate bilaterally with a worker. These negotiations represent the outcome of more informal recruitment channels, where employers talk personally to potential workers that have been referred to them by other employers in their network. In the experiment, every employer that indicates a wish to negotiate bilaterally is assigned a different randomly selected worker. Each of the selected workers is then asked whether she wants to enter the bilateral negotiations. After all workers have reacted, the bilateral wage negotiations and the centralized market open simultaneously. All employers and workers that have not been paired for bilateral negotiations -either because the employer has not asked for it or because the solicited worker has declined- enter the centralized market. ${ }^{15}$

The centralized market is organized as a standard double auction -first studied experimentally by Smith (1962)- in which both employers and workers are able to make public wage

\footnotetext{
${ }^{14}$ The 'currency' in the experiment is called 'experimental franc'. Francs are exchanged for euros at the end of the experiment at a rate of 15 francs $=€ 1$.

${ }^{15}$ Note that with five workers and four employers there is always at least one worker not involved in bilateral negotiations.
} 
proposals at any time during a market period. In this market there is complete anonymity in trading relations. ${ }^{16}$ We chose the double auction, because it is usually considered by experimental economists to be the institution that best embodies the characteristics of markets where prices and transactions come about through an equilibrating process. Bids and asks in the double auction consist of an integer between 0 and 50, inclusive; these wage proposals are public (hence, the centralized character of these markets). If a market wage proposal is accepted then a labor contract is established. Participants have 90 seconds to reach agreements. After all possible contracts have been realized or 90 seconds have passed (whichever comes first), the market closes. For the cases where an agreement has been reached the worker then determines an effort level (e), with resulting payoffs as explained above. The chosen effort level is communicated only to the employer and worker concerned. Neither knows the identity of those making or accepting offers, nor do they know the history -of wage or effort levels- of any of the other market participants. Note that the double auction is not intended to precisely replicate markets observed in the field. Instead, they are what Granovetter (1985:484) calls "idealized markets" that are void of any significant effects of social relations between employers. The only social relations that can occur between any specific employer and worker are those that arise after a wage proposal has been accepted (i.e., a work relation has been established). Taking this idealized market form allows us to experimentally isolate the effects of social relations in the alternative -informal- channel, the bilateral negotiations.

In these bilateral negotiations a single employer and a single worker are linked. The employer makes a bilateral wage offer to the worker it is paired with, which - like in the market- consists of an integer between 0 and $50 .{ }^{17}$ The worker concerned can then accept or reject this offer. Employers and workers involved in the bilateral wage negotiations can at all times observe the offers made and contract wages agreed upon in the public market. In contrast, participants in the market are not informed about what is happening in the negotiations; this represents the transparency of a market and the lack of it in bilateral negotiations. The employers whose offers are rejected and the workers that have rejected immediately enter the idealized market and join the employers and workers that have not engaged in bilateral negotiations. This is organized in a way, that the latter cannot recognize

\footnotetext{
${ }^{16}$ To ensure this anonymity across rounds, participants' positions on the monitor are randomly reallocated in every round.

${ }^{17}$ Note that the initiative is on employers' side in the bilateral negotiations, in the sense that they decide whether to offer negotiations in the first place and also make the wage offers. This asymmetry reflects the basic power relations present in the labor market (Western 1998; Streeck 2005).
} 
them as newcomers in the market. After the bilateral agreements have been reached, the workers choose an effort as described above.

A crucial difference between the idealized market and bilateral negotiations is that in the latter case information about a worker's previous effort choices may be obtained. This is how these negotiations represent the main characteristic of the informal recruitment channels described above. As explained above, our interest in this paper is in how and under what circumstances a social structure of employers can arise where such information is shared.

After employers and workers have been paired for bilateral negotiations each employer asks all other employers in their group for their information about the effort levels they had experienced by that particular worker in the past. This request is automatically generated in the experiment because our main interest lies in the employers' willingness to share information and not so much in their desire to request it. ${ }^{18}$ Each employer who is asked can either say yes or no to the information request. Specifically, the information each employer can give is a truthful revelation of the number of a worker's high effort choices in relation to the total number of previous labor contracts with that employer. This information includes those jobs in which the contract with an employer had taken place through the idealized market but excludes the decisions of the first 10 rounds which will be explained below.

When employer A is asked by employer B to provide this information, we first tell A what it is, i.e., how often $\mathrm{A}$ has reached an agreement with that worker and how often this was followed by high effort. The worker remains anonymous and cannot be recognized by $\mathrm{A}$ in future interactions. This is important, because it ensures that the information cannot be used for direct reciprocation by employer A of this worker's past efforts. Moreover, employers are not informed of wages earned previously by the worker. The main reason is that we think that this is the way in which information is shared amongst employers in naturally occurring labor markets. For example, a typical conversation between two employers on the golf course will reveal information about whether the worker concerned is trustworthy but not about the wage this worker earned in the previous job.

As explained above, our treatments differ with respect to the conditions under which information can be released (see table 1). In the sessions with identification employers are tagged with a code and the code of an employer taking part in information transfers is revealed to the other employer involved in the transfer. Given the dynamic structure of our

\footnotetext{
${ }^{18}$ Because requesting information is costless but useful in our experiment, it is likely that most employers would do so anyway. By automatically generating the request, we reduce the noise in our data. Relaxing this assumption is an obvious extension to be explored in future research.
} 
environment, this makes it possible to keep track of others' behavior over time. In contrast, without identification of employers, both employers that ask for information and those that agree to give it do so without any other participant being able to keep track of this decision.

In the sessions with costly information an employer that decides to give information has to pay a fixed cost of 0.3 francs every time she does so. This reflects the financial costs or time spent on looking for information and putting it into the form that is needed, e.g., writing a recommendation letter (Marsden 2001). Note that these costs are low relative to the joint earnings from any single labor contract (10 or 30 francs). In the sessions with costless information there are no charges associated with information flows.

Until now, we have described the 20 rounds that are central to our study. These are preceded by 10 initial rounds that allow participants to establish a clear expectation about the workings of the idealized market. This is important, because not many participants will have experience with such markets (in contrast to employers in the field, who likely deal with markets very regularly). Moreover, these rounds provide us with information about behavior in situations where recruitment takes place only through idealized markets. This will provide us with a benchmark to which we can compare the workings of the idealized market when an alternative recruitment channel exists. In these first 10 rounds there is no possibility of negotiating bilaterally and also no possibility of information sharing between employers. All trading activity takes place through the idealized market, which works just like the one for the following 20 rounds of the sessions. After the 10 market rounds are over, participants receive new instructions in which the new situation is laid out for each of the new 20 rounds. Participants are told at the beginning of a session that there are a total of 30 rounds and that after the first 10 rounds they will receive new instructions.

A summary of the experimental design is given in Figure 1. See Appendix A for a translation of the instructions.

[Figure 1 here]

\section{RESEARCH QUESTIONS}

As mentioned in the introduction, the focus of our study is on how and under what circumstances social relations amongst employers facilitate the dissemination of information about workers' trustworthiness and how such relations affect the choice of recruitment channel and the resulting trading quality. Having presented our experimental design we can now formulate three fundamental research questions: 


\section{How much information is shared and why?}

2. What kinds of information networks arise?

3. What is the effect of information sharing on the employer-worker relations?

The first two questions are concerned with the social relations between employers while the third focuses on the social relations between employers and workers. For all three questions, we will consider the effects of the information network properties: identifiability and costs.

More specifically, our approach will consist in using treatment differences in the data to understand the mechanisms underlying observed behavior. With respect to our first research question we will look both at fractions of information requests honored as well as at the determinants of the decision to provide information when asked. Two possible hypotheses are that (i) the absence of identification and (ii) the presence of information sharing costs will hinder the emergence of significant levels of information exchange. The rationale behind (i) is that an important mechanism like reciprocation of other's provision of information is impossible without identification. The rationale behind (ii) is that employers, even when it is possible to identify others, may not be able to reap sufficient benefits from information exchange to compensate for the corresponding costs.

With respect to the second research question we can hypothesize that the treatment variables (i.e., network properties) will influence the structure of observed networks. Across treatments, distinct kinds of information networks can arise. An important distinction is between those that can be formed when no identification is possible and those that can occur when employers can identify one another. Without identification, employers cannot commit to sharing information (only) with specific others and only networks can occur, in which employers remain anonymous to each other. In these 'anonymity networks', information provision is in nature a collective good from which no one can be excluded. Identification on the other hand, will allow employers to reciprocate leading to what we call 'reciprocity networks'. This will however also depend on the costs of sharing information. Consistent with our discussion of the first question, we thus posit that with identification and without costs larger and more closed networks will arise. This means that more employers will share information and that the resulting networks will tend to be closed in the Coleman (1988) sense. ${ }^{19}$

Finally, we will examine how workers' wage levels and trustworthiness (measured by their effort levels), and employers' earnings depend on the degree of information sharing and on the network structures that emerge. Here, our hypotheses are that significant information

\footnotetext{
${ }^{19}$ Recall that closure measures the extent to which any two agents connected in a network both have connections to the same third parties (Karlan et al. 2009).
} 
exchange leads to more trading through the informal channel, higher trustworthiness, and higher earnings for both workers and employers. These effects are expected to be stronger, the larger and more closed the information network is. The rationale behind these hypotheses is that in the environment we study, connections and the information generated thereby can only be useful if an employer recruits through the informal channel. The higher the level of information exchange about the trustworthiness of prospect workers, the higher the probability that employers will reward workers (i.e., through high wages) based on indirect reciprocation of their efforts in the past. This in turn will lead to higher effort levels by the workers because they will reciprocate employers' rewards with more trustworthy behavior. As a result, the overall earnings of both employers and workers will be higher when recruiting through the informal channel than the formal one. Consistent with our hypotheses for questions 1 and 2, we predict that these effects will be strongest in the case of a network structure with identification and without costs.

\section{RESULTS}

In this section we present the results in detail. In the discussion section, we will interpret these results and relate them to our research questions and hypotheses, and to the literature discussed above.

\section{Information Sharing}

Table 2 gives a first impression of the extent of information sharing across treatments. Recall that every time an employer decides to enter bilateral negotiations, she automatically asks the other employers for information. Table 2 shows the fraction of these requests that are positively responded to.

\section{[Table 2 here]}

The results show that, in this very aggregated view, the distinction between costless and costly information is more important than the effect of identification. When information sharing is costless it is high overall. When it is costly just over half of the requests are honored.

To better understand what goes on in the different treatments we need to look at information sharing in more detail. Table 3 gives a view of information flows in one particular group -group $1-$ of the identification/costly treatment. ${ }^{20}$ Each cell shows the

\footnotetext{
${ }^{20}$ Appendix B contains the tables corresponding to all groups in this treatment. This is the treatment with the highest variation in observed networks. Similar tables for other treatments are available upon request.
} 
fraction of information requests that was honored between each two employers of the total of four employers in the group.

\section{[Table 3 here]}

Inspection of the entries in table 3 suggests the occurrence of reciprocal behavior in the provision of information. For example, employer A responds positively to all information requests by $\mathrm{B}$ and most ( $82 \%$ ) by $\mathrm{D}$, while employers $\mathrm{B}$ and $\mathrm{D}$ also provide information to $\mathrm{A}$ most of the time. In contrast, employer C provides little information to A $(20 \%$ of the requests are responded to positively) and A only gives information to $\mathrm{C}$ in response to $38 \%$ of C's requests.

To quantify this reciprocity in the provision of information we consider a summary statistic based on numbers such as those reported for group 1 in table 3. Consider pairs of employers, $\mathrm{X}$ and $\mathrm{Y}$ that are together in a group. Let $\mathrm{f}_{\mathrm{XY}}$ denote the fraction with which $\mathrm{X}$ gives information to $\mathrm{Y}$ and $\mathrm{f}_{\mathrm{YX}}$ the fraction with which $\mathrm{Y}$ gives information to $\mathrm{X}$. For example, in table $3, \mathrm{f}_{\mathrm{AB}}=1$ and $\mathrm{f}_{\mathrm{BA}}=0.73$. For each treatment we then determine the correlation coefficient between $f_{X Y}$ and $f_{Y X}$ for all possible pairs of employers $X$ and $Y$ (where $X$ and $Y$ are in the same group). A larger-positive-correlation coefficient indicates a higher level of reciprocation within a treatment. Table 4 shows these correlation coefficients.

[Table 4 here]

First consider the treatment without identification where information is given costlessly. Here, the correlation between information given and information received is -0.20 with a two-sided significance of 0.233 . This lack of statistically significant correlation has an intuitive explanation. From table 2 we know that the general levels of information sharing are high in this treatment ( $91 \%$ of the information requests are honored). Given that providing information is costless, employers are happy to do so if requested, without requiring reciprocal behavior. In fact a reciprocal response directly to the sender is impossible because in networks without identification one cannot determine who the sender of information is.

Similarly, in the treatment with costly information and no identification, one cannot determine who the sender of information is. Yet, the correlation is 0.31 with a two-sided significance of 0.068 . In this case, the marginally significant positive correlation is the result of the fact that groups as a whole vary in their behavior. In some groups employers abundantly share information and in other groups the employers hardly provide information at all. What appears to be happening is a kind of 'collective' reciprocity at the group level where 
employers respond positively (negatively) to high (low) overall levels of information provision in their group. Differences across groups then yield the (marginally) significant correlation coefficient across all groups in this treatment.

In the treatment with identification where information is costless the correlation coefficient is 0.13 with a two-sided significance of 0.527 . Again, no reciprocal behavior is observed, even though identification allows one to reward the sender of information. With costless information provision employers are again generous in providing it (table 2 shows that $94 \%$ of the requests are honored in this treatment cell).

Finally, in the treatment with costly information and identification the correlation is 0.56 and highly significant with a two-sided p-value smaller than 0.001 . When employers know who gives them information and that this giver paid a cost to do so, reciprocal behavior in the form of sharing the own information with that other employer does emerge.

To further explore the reasons for sharing information, we explain the individual decision whether or not to respond positively to an information request by a set of explanatory variables. For this purpose we use a random effects probit regression. We apply this only to the treatment with identification and with costly information, because this is the case where a variation in responses (it is given in 52\% and withheld in $48 \%$ of the cases) is combined with a variety of independent factors that may influence this decision (including previous decisions to share information of the employer asking for information). Table 5 gives the results of this regression.

[Table 5 here]

Note that all of the estimated coefficients in table 5 are statistically significantly different from zero at the 5\%-level or better. There is a clear intuitive explanation for the sign of each of them. First, employers tend to decrease their willingness to participate in an information network as the rounds proceed. This may be explained by the fact that these networks are no longer important after the experiment has ended. Second, an employer active in the idealized market is less likely to provide information. Such an employer is more likely to prefer this channel than the average employer and therefore less likely to have any use from information sharing. Third, the large positive and strongly significant coefficient for the information requestor's most recent decision is direct evidence of reciprocal behavior. Finally, having earned more in a previous contract makes it relatively easier for an employer to bear the costs of providing information. 


\section{Information Networks}

In the 12 groups without identification, only anonymity networks can arise. We observe no 'no-information networks', i.e., without any information sharing. Moreover, only one 'fullinformation network' occurs (one of the groups with costless information), where information requests are always honored. The other (11) groups are in between these extremes and can be characterized as 'partial-information' or 'incomplete' networks. There is a difference between the case where information is costless and that where it is costly, however. As shown in table 2 , the amount of information given is higher $(91 \%)$ in the former case than when information provision is costly (59\%). This difference is statistically significant at the $5 \%$-level using group averages as cases (Mann-Whitney $\mathrm{U}=3.00, \mathrm{~N}=12, \mathrm{p}=0.016$ ).

If the employer that requests or gives information can be identified, a large variety of networks can be formed. In our treatment without costs of information provision we basically observe only one kind, however. This is an almost complete network where information is always given when asked (in aggregate it is given $94 \%$ of the time; see table 2). Note that these networks are almost completely closed in the sense that every employer is connected (through information provision) to every other. We only observe in one group (out of 5) that the network is completely closed in this sense, however. The $6 \%$ of the information requests that are not honored are equally spread across the other groups.

The treatment with the highest divergence of information networks formed is with identification and costly provision. For this case, we discuss the information networks observed in more detail. The precise patterns of information provision in each group in this treatment are presented in appendix B. To study structures of information networks, we need to define what we mean by a network connection between two employers. We measure this by the regularity of information sharing. To keep the analysis tractable, we dichotomize the relationship between any two employers and define them as either having a network connection or not (as in Goeree et al. 2008). Specifically, we will say that an employer has a $50 \%$-network connection with another employer if these two employers give each other information in at least $50 \%$ of the opportunities. ${ }^{21}$ If one or both employers in a pair was never asked to provide information (which may occur if an employer always hires via the idealized market), we consider them not to be connected in this sense. Note that a maximum of six 50\%-network connections are possible for each group (because there are 4 employers

\footnotetext{
${ }^{21}$ To check the robustness of our classification, we will also (in the next subsection) investigate the effects of using a stricter definition of a network connection. Specifically, we will say that an employer has a 80\%-network contact with another employer if these two employers give each other information in at least $80 \%$ of the opportunities.
} 
per group). Appendix B gives for each group all 50\%-connections that we observe. Across the nine groups in this treatment, the average number of such connections is 1.7 , varying between 0 (groups 5 and 9, cf. appendix B) and 5 (group 4).

Using the concept of 50\%-network connections, we can consider the extent of closure in the information networks. For this analysis, we disregard the two groups without connections. There are three groups $(6,7,8)$ with only one connection. These have complete closure in a trivial sense, because neither of the two connected employers connects to any third party. The two groups with two connections are by definition completely open information networks (because the two employers in either connected pair do not both connect to the third party). Group 3 has three connections and turns out to be a completely open network. Finally, group 4 (with five 50\%-network connections), is a partially closed network, where connected employers on average connect to the same third party in $60 \%$ of the cases. By and large, the network structures are stable across rounds. If we define 50\%-network connections based on the final 10 rounds only, results very similar to the ones described here are obtained.

\section{Employer-Worker Relations}

We now turn to the effects that information networks have on the employer-worker relations. We first give an overview of the recruitment channel used, wage levels, worker trustworthiness and earnings of employers and workers. The focus is on how levels of trustworthiness and employer and worker earnings in the informal channel compare to those in the idealized market and how this varies with the treatment variables (i.e., network properties). Later in the section we will dig deeper into the two treatments with costly information sharing and analyze how employer-worker relations are affected by the variations of the information networks that arose.

Table 6 shows average values of key variables for all four treatments.

\section{[Table 6 here]}

We will discuss each row in turn. The second and third rows of the table show that the fractions of overall realized contracts are quite similar across the four treatments. Moreover, in all treatments almost all contracts are established. The fourth row shows that recruitment through the informal channel is considerable, the lowest value (and the only case where a majority of contracts is made in the idealized market) being almost $38 \%$ for the treatment with identification and costly information. Comparing across treatments the fraction of labor contracts made through these informal recruitment channels to the level of information sharing (table 2), note that distinct levels of information are not the sole cause of differences 
in channel choice. For example, without identification, much more information is provided when it is costless than when it is costly, but fewer contracts are made via the informal channel. Hence, to understand the effects of information we need to take the information network and its structure into account.

Rows 5-16 show averages for workers' wages, their effort levels and the earnings of workers and employers. By comparing values in rounds 1-10 to those in rounds 11-30, one can see the difference that the existence of the informal recruitment channel makes. Rows 5-7 show that in all four treatments wages are considerably higher in the informal channel than in the idealized markets.

Rows 8-10 reveal that the fractions of worker's high effort choices after having been recruited through the informal channel are also substantially higher for all four treatments than after a contract has been established in the idealized market. In other words, recruitment via informal channels leads to more trustworthy behavior in all treatments. In turn, this leads to higher overall earnings in the informal channel, as we will discuss below.

In contrast, the comparison between wages and effort levels in the idealized market when it is the only recruitment channel (rounds 1-10) to when there is also an alternative (rounds 11-30) shows only small differences and in different directions for distinct treatments. In other words, trustworthiness in jobs recruited via the idealized market is not systematically affected by the fact that one's choice may be reported to other employers in the future. ${ }^{22}$

The last six rows of table 6 , rows 11-16, give the earnings' patterns for both employers and workers. Comparing first the earnings levels in rounds 1-10, when recruitment is only possible via the idealized market, to earnings in contracts that result from the informal channel in rounds 11-30, one can see that both employers and workers earn more after recruitment through the informal channel. Hence, the emergence of recruitment via informal channels is economically beneficial for both sides of the market.

Comparing earnings in more detail, the results show that employers' earnings increase from rounds 1-10 to rounds 11-30, regardless of whether recruitment takes place via the idealized market or through the informal channel in the latter case. In three out of four treatments these earnings are higher for contracts from the informal channel than for those that are made in the idealized market. For the workers the comparisons are different. Their earnings increase from rounds 1-10 to rounds 11-30 only if in the latter case they engage in contracts through the informal channel. Earnings from contracts in the idealized market are

\footnotetext{
${ }^{22} \mathrm{We}$ will argue in the following section, that this lack of significant effect is, in fact, the net result of two counteracting forces.
} 
lower in rounds 11-30 than in rounds 1-10. We will discuss explanations for this phenomenon in the next section.

Now we provide further analysis on how employer-worker relations are affected by the variations of the emerged information networks. First we look at what occurs in the networks with costly information sharing. For these treatments we found positive correlations in information sharing indicating reciprocal patterns between particular employers. We start with the case without identification, for which we concluded above that this reciprocity was at the group level. We want to further explore the heterogeneity across groups in this treatment. Table 7 shows averages for trading activity in each of the six groups, ranked from most to least information shared.

\section{[Table 7 here]}

One can see by inspection how the average fraction of information given is directly and positively related to the percentage of contracts agreed upon in the informal recruitment channel. Observe also that in group 3, where the percentage of information given is very high, recruiting through the informal channel leads for both employers and workers to much higher earnings than in the idealized market. For workers this holds in five out of six groups. Employers earn more from informally recruited contracts than in the idealized market in only two of the six cases. In the other four groups, they do earn more on average after having recruited informally than in the first ten rounds, however (this is not shown in the table). Therefore, the introduction of an informal channel is (financially) beneficial to employers even if their earnings are lower when they use this channel than when they do not. Nevertheless, when both channels co-exist it appears that a very high level of (anonymous) information sharing is needed for trades in the informal channel to be more profitable for employers than trades via an idealized market. We will further discuss this issue in the following section.

Next, turn to the case of costly information and employer identification. Here, we observed a rich variety of information networks. The question to be addressed is whether endogenously formed information networks benefit those involved in the network. In other words, do employers that share information earn more than those that do not? To study this issue we need a measure for the regularity of information sharing, for which we use the $50 \%$ network connection criterion and the $80 \%$ - variant thereof as defined above. For each of these measures we count the number of connections that each employer has, which for each employer will be an integer number between 0 and 3 . 
Table 8 shows the results of two random-effects GLS regressions of employer earnings on a number of exogenous variables; the earnings variable is net of the costs of providing information (i.e., does not correct for these costs).

[Table 8 here]

Both regressions include the same dummy for use of the informal recruitment channel, but differ in the connection variable as well as in the interaction term between connections and informal recruitment. In one case the number of 50\%-network connections is used and in the other case the number of $80 \%$-network connections is used. In the environment that we study connections can only be useful if an employer recruits through the informal channel, so that our a priori prediction is that the coefficient for the (un-interacted) dummy for the number of connections will not be significantly different from zero. The same zero-prediction applies to the (un-interacted) informal channel variable, since in the absence of connections there is little difference between recruiting via the idealized market or via the informal channel. In contrast, we expect the interaction effect to be significantly positive; with connections, recruiting via the informal channel should be advantageous (and vice versa). The regression results are consistent with our predictions: for both levels of connections there is a positively significant effect of the interaction term but not of the separate variables. ${ }^{23}$ In other words, employers that have built up a strong information sharing network benefit from recruiting through informal channels. One implication is that employers are able to use reciprocal relations to create profitable networks for information sharing.

One can also compare employer earnings for distinct levels of closure. To do so, we consider the seven groups where we could define the extent of closure, as described above. Recall that we determined for four of these groups that they were open, while three were closed and one was partially closed. Employers in the open networks earned on average 5.9 francs per contract, those in closed networks earned 7.2 on average and employers in the one partially closed group earned on average 1.4. The difference between earnings in the open and closed groups is statistically significant $(\mathrm{Z}=-1.96, \mathrm{~N}=6, \mathrm{p}=0.05) .{ }^{24} \mathrm{We}$ conclude that, in addition to our previous finding that the number of network connections has a positive effect on earnings when recruiting in the informal networks, closed networks also yield higher

\footnotetext{
${ }^{23}$ More precisely, to test whether the combined effect is significant, we check whether the sum of the coefficients for uninteracted terms plus the interaction term is significantly different than that for the term reflecting participation in the informal channel alone. For the $50 \%$-variable this is the case at $p=0.6$, for the $80 \%$ variable at $\mathrm{p}=0.03$.

${ }^{24}$ One should keep in mind, however, that this significance is based on asymptotic properties, while we have only 6 (group) observations.
} 
earnings than open ones. Though we have only one (group) observation for a partially closed network, it is noteworthy that employers in this group earn less than in either open or closed networks. It is interesting that closure benefits participants in a network. Traditionally, closure is beneficial to network participants because it enables effective punishment of bad reputations (Coleman 1988). In our networks, the reputations that are relevant in this respect are related to the extent that specific employers share information. These are only privately known (i.e., not shared in the network). This limits the effectiveness of punishment in the Coleman sense but does not destroy it.

\section{Overall summary of the results}

Our results show a considerable level of information sharing. Depending on the properties of the information network, between $50 \%$ and $95 \%$ of the information requests are met with a positive response. The level of information sharing is considerably higher (more than $90 \%$ ) when information transmission is costless than when it is costly $(50 \%-60 \%)$, but it is unaffected by the possibility of employer identification. With identification, the number of network connections an employer has positively and strongly affects the trustworthiness of the workers she hires. Specifically, employers that share information hire workers that are more often trustworthy than others. ${ }^{25}$ As a consequence, employers that recruit through informal channels earn on average more than those who do not. Workers hired informally earn more than those hired through the formal channel.

\section{Discussion}

We structure the discussion of the implications of our results along the lines of the three fundamental research questions distinguished above.

\section{How much information is shared and why?}

As a preliminary point, note that -by design- information is only shared in the informal recruitment channel. The reason that we decided not to enable information sharing in the idealized market is that outside the laboratory access to other employers' information is much more difficult when recruiting through more formal, impersonal channels. Laboratory control

\footnotetext{
${ }^{25}$ Note that some levels of trust and trustworthiness emerge in the social relation between employer and worker even without information sharing. This occurs in a substantial minority of cases $(25 \%-40 \%)$ and was previously observed by Fehr et al. (1993).
} 
allows us to isolate this difference between the two channels by not allowing for any information sharing in the idealized market.

We can summarize the information sharing we observed as follows. First, as hypothesized above, the existence of costs reduces the extent of information exchange. Second, contrary to what we hypothesized, the absence of identification does not hinder information sharing. Third, when information is costless, it is given very often. Fourth, when it is costly, the specific social structure of information sharing depends strongly on whether employers can identify each other.

We interpret these findings as follows. In networks where identification is not possible and information provision is costless, almost every employer shares the information requested. Though this finding supports a more material motive, we find that a majority of the employers are also willing to share costly information, even when anonymity prohibits future reciprocal responses. Other mechanisms than the mere effect of material incentives appear, therefore, to be at play in explaining this generosity in information sharing. Employers in these anonymous groups seem to have established a general norm of information provision as a contribution to a collective good (Lawler and Yoon 1996). The main mechanism underlying employers' adherence to this norm may well be their pro-social motivation generated by social relations that employers within a network are embedded in (Granovetter 1985). A typical employer is willing to bear the costs of sharing information if enough others are willing to do the same. This yields considerably distinct social structures across groups. In some groups the result is a complete information network while in others sharing breaks down completely.

The observation that the social structure emerging between employers that cannot identify each other is less driven by material incentives than by common interests (Raub and Weesie 1990) provides more support for the social embeddedness line of reasoning (Granovetter 1985; Uzzi 1997) than for Coleman's argument (Coleman 1988) that reputation building is an important precondition for exchange within a social structure. In our experiments without identification, employers' willingness to share information is clearly not an outcome of reputation building (which is impossible without identification).

When identification is possible and provision is costless, information is almost always shared. Employers do not want to be recognized as being unwilling to share it. Importantly, in the case with identification and costly provision a similar aggregate level of information sharing is reached as in the case without identification, but through a different mechanism and leading to a completely different social structure. Now, information sharing is based on direct 
reciprocation of others' decisions to provide it. When employer A is deciding whether or not to honor an information request by $\mathrm{B}$, the most recent response by $\mathrm{B}$ to a request by $\mathrm{A}$ is one of the most important factors. Identification enables (private) reputation building, which in turn enables reciprocity. The combination of the two yields information sharing. Reputation should not matter for employers who prefer to recruit through formal channels (because in our experiment they do not request information). Indeed, our data show that they are less likely to share information when asked. For the employers that do use the informal recruitment channel, the interaction between reputation and reciprocity yields an interesting variety of information networks across groups. This shows that employers are able to endogenously form social structures that meet the specific needs and characteristics of their group. We can conclude that with identification, Granovetter's social embeddedness paradigm is less important than Coleman's argument that reciprocity through sanctioning and rewarding of reputations is the mechanism driving our results. ${ }^{26}$

\section{What kinds of information networks arise?}

A consequence of the distinct ways that employers decide on whether or not to give information, is that we can classify the networks that emerge in two general categories of social structure: (i) those where information is anonymously and voluntarily provided as a collective good; we have called these 'anonymity networks'; and (ii) reciprocity-based information sharing networks, which we have called 'reciprocity networks'. This distinction runs parallel to our experimental treatments. Without identification, reciprocity-based networks cannot be formed. In either type of network, the extent to which information is actually provided varies with the costs of providing it.

Interestingly, reciprocity networks seem to crowd out anonymity networks in the sense that unconditional provision becomes rare and employers look to form networks of mutual information sharing. This finding supports Granovetter's (1985) argument that identification is not necessary for the emergence of networks and may even be harmful. The harm occurs because pro-social motivations are crowded out by more interest-driven type of motivations like reputation building. In the end, when information is costly and identification allows for reputation formation the result is a large variety of reciprocity networks across groups,

\footnotetext{
${ }^{26}$ Importantly, in our treatment with identification reputation is private, in the sense that one only knows if a particular other employer provided information in response to one's own requests. Responses to requests by other employers remain unknown. A different notion of reputation is one where some indication of the willingness to share information is publically known. It would be easy to extend our experiment by allowing for public information on all responses to information requests.
} 
varying from completely open to completely closed. Note that this does not support our hypothesis that networks in this treatment will tend to be closed.

Social relations developed in both types of networks have instrumental value to employers by providing them with information (i.e., social resources) they can access and utilize in a social structure. This type of 'instrumental' social capital complements other types such as the instrumental advantages to the firm in utilizing its employees' social networks (Fernandez et al. 2000; Erickson 2001). There is differential access to this social capital, however. While in the anonymity networks every employer can contribute to and benefit from the information provided as a collective good, in the closed social structure of reciprocity networks some employers are excluded from the benefits of information sharing. The distinction between anonymity and reciprocity networks therefore has important implications regarding social equality and fairness (Bourdieu 2000; Streeck 2005). The exclusion of some employers is an example of differential access to the social capital (Lin 1999, Flap and Boxman 2001), which in turn implies differential access to and thus social inequality among employers in finding trustworthy workers. Note that in our case this differential access emerges endogenously and is based on employers' own choices in providing information to others.

\section{What is the effect of information sharing on the employer-worker relations?}

As hypothesized above, the information networks formed lead to higher wages offered and more trustworthiness of workers in contracts made in the informal recruitment channel than in the idealized market. These higher wages and trustworthiness lead to higher worker earnings in all treatments. The driving force is that in the informal recruitment channel, the information networks enable indirect reciprocity by employers of workers' efforts in the past. As a result, employers can selectively offer high wages to trustworthy workers. As for employers' earnings, in three out of four cases, these are higher when recruiting through the informal channel than through the formal channel. This is driven by direct reciprocation by trustworthy workers who were offered a high wage in the first place. In all cases, however, when there are two channels to choose from employers earn on average much more in either channel than when they can only recruit through the formal channel. The fact that they benefit can be attributed to the information sharing that occurs after introduction of an informal recruitment channel. ${ }^{27}$ In particular, their high earnings in the informal channel are due to employers'

\footnotetext{
${ }^{27}$ It is important to note that it is really the information sharing that causes the effects we observe after introduction of an informal channel (i.e., after round 10). In Schram et al (2010) we added a treatment where bilateral negotiations were introduced after round 10 but no information was provided whatsoever. The result
} 
ability to pinpoint trustworthy workers using the information shared. This is an important way in which the social relations between employers affect the relations between employers and workers, and in fact benefits both. Note that these findings support the hypotheses that we put forward above when discussing our research questions. They are also in line with the instrumental social capital literature on both the demand (Fernandez et al. 2000; Erickson 2001) and supply side (Lin et al. 1981, 1999) of the labor market. The social capital employers utilize from their endogenously formed networks and the informal negotiations between employers and workers make them both better off.

What remains to be explained are the observed patterns for wages and trustworthiness in the idealized market before and after introduction of the informal channel. These patterns may be driven by two counteracting forces. First, there is a selection of trades in the informal channel compared to the idealized market. Employers are aware of the fact that untrustworthy workers (those unwilling to provide high effort) will not go to the informal channel, or at least will not be successful there if information sharing amongst employers reveals their past record. Aside from the direct effect that trustworthiness in the idealized market will be lower after the possibility of recruiting through an informal channel has been introduced, this puts downward pressure on wage offers in the market. This is because employers will not want to offer a high wage to an untrustworthy worker. These lower wages in the market will themselves reinforce the tendency of workers to choose low effort. On the other hand, given the possibility that recruitment may take place through the informal channel in the future, workers also need to build up a positive reputation of trustworthiness to obtain future high wage offers. After the informal recruitment channel has been introduced, they will therefore be less inclined to exploit a high wage by giving low effort and this tendency may lead to employers offering high wages in the idealized market. The net effects of these two forces on wages and trustworthiness in the idealized market may be positive or negative. This explains the diverse results we observe across treatments. For example, we observe in our data that the net effect on trustworthiness is positive in three out of four cases: only when identification is not possible and information provision is costly does the introduction of an informal recruitment channel lead to a decrease of trustworthiness in the idealized market (table 6).

was that there was no difference between the first 10 and final 20 rounds (in fact, bilateral negotiations were barely used at all). 


\section{CONCLUSIONS}

We have used experiments to create a setting in which we can systematically study how social structures between employers emerge that increase the quality of the worker-employer relation in recruitment. This is an important example of how sociological concepts that have traditionally been neglected by economists may have a major impact in an area that many economists consider to be central to their discipline (as do sociologists, of course). On the other hand, our structuring of the idealized markets, the informal channel, and the information flows (including the costs thereof) follow the tradition in economics and may thereby contribute to the understanding of the sociological processes involved. Hence, by exploring both sociological and economic mechanisms at work this research hopes to provide a demonstration of how an interweaving of the two disciplines can benefit both.

Laboratory control has allowed us to link observed patterns at the macro-level to the features of the interaction between individuals at the micro-level. In particular, we have shown how information sharing and the fruitful use of informal recruitment channels emerge from individuals' decisions and how, in turn, the resulting social structures condition the behavior of the same individuals. Our experimental results demonstrate that the existence of employer information networks can benefit both employers and workers. These information networks provide employers with instrumental social capital they utilize in hiring trustworthy workers through the informal channel, which leads to higher earnings for both than when recruiting only through the formal channel. In this way, our study complements the existing literature on instrumental social capital and its effect on the employers' side of the labor market (Fernandez et al. 2000; Erickson 2001; Flap and Boxman 2001).

Our results also illustrate how specific network properties affect the functioning of information networks. When information transmission has no cost, one can say that a general norm of sharing information develops. When providing information is costly, pro-social motivations and (direct) reciprocal behavior explain information sharing. Which of the two mechanisms is at work depends on whether or not employers in the network can identify one another. If they cannot, pro-social motivations generated by the social relations within the network employers are embedded in explain their adherence to a general norm of information sharing. If they can identify one another, information sharing is explained by reciprocal behavior in response to the reputation of the employer requesting information. It is precisely this distinction in the identifiability of others in the network that enabled us to separate the impact of these two mechanisms on the emergence of social structure. By doing so, it also 
helped us to investigate which of the paradigms - Coleman versus Granovetter- was better able to explain the behavior we observed in the laboratory. We conclude that neither is exclusive, the explanatory power strongly depends on the properties of the social structure.

We have focused on the case of employer information networks, and one may ask to what extent our insights apply to other cases. Indeed, problems of information sharing like the ones we study are present in other areas of society. For example, in the relations between debtors and creditors on the credit market similar issues of information transmission exist (Brown and Zehnder 2005; Karlan et al. 2009). In this case, potential information sharing between financial institutions is affected by third parties, like credit rating agencies. The labor market is surely different from the credit market, since the nature of social relations is not the same in the two spheres. However, the fact that the access to information is heavily influenced by social structure is common. Modification of our experimental environment can be used to fruitfully study such other cases.

More generally, one may wonder about the external validity of our experimental design. How do networks in our laboratory relate to networks in the field? Though one should be careful when generalizing our experimental results, they have important implications. By carefully structuring the experiment based on networks in the field, while stripping as many 'unnecessary' characteristics as possible, we have been able to draw causal inferences about the mechanisms underlying the emergence of such networks. This is an example of how the lack of external validity in comparison to field studies is compensated by a higher internal validity (Schram 2005). Moreover, by enhancing the incentive compatibility of participants' actions, experimental findings like ours have been shown to be robust across design variations, which relaxes the external validity concerns (see Buskens et al. 2010 for a discussion). Nevertheless, future research should directly check the robustness of our results by carefully re-introducing features of networks observed outside the laboratory.

Many directions for such future work are possible, and can be based on various changes in the experimental procedures. For example, one could add communication and/or face-to-face contact to the information sharing phase of our experiments. This could lead to various types of sanctioning of employers that do not share their information, which may strongly affect the nature of the social relations that develop. In addition, exogenously imposed asymmetric access to the information network could lead to important inequality issues. Finally, one could create a possibility of information sharing on the supply side of the labor market by letting workers share their experiences with specific employers. 


\section{REFERENCES}

Baker, G.P. (1992), "Incentive Contracts and Performance Measurement," The Journal of Political Economy 100-3: 598-614.

Bandiera, O, I. Barankay and I. Rasul (2009), “Social Connections and Incentives: Evidence from Personnel Data," Econometrica 77: 1047-94.

Bandiera, O, I. Barankay and I. Rasul (2010), "Social Incentives in the Workplace," Review of Economic Studies 77(2): 417-59.

Bourdieu, P. (2000), Les Structures Sociale de l'Économie. Paris: Editions du Seuil.

Bowles, S. and H. Gintis (2004), "Persistent Parochialism: Trust and Exclusion in Ethnic Networks," Journal of Economic Behavior and Organization 55(1): 1-23.

Brandts, J., K. Gërxhani, A. Schram and J. Ygosse-Battisti (2010), “Size Doesn’t Matter! Gift Exchange in Experimental Labor Markets," Journal of Economic Behavior and Organization 76: 544-548.

Brandts, J. and G. Charness (2004), "Do Labour Market Conditions Affect Gift Exchange? Some Experimental Evidence," Economic Journal 114: 684-708.

Brauna, N. and T. Gautschi (2006), "A Nash Bargaining Model for Simple Exchange Networks," Social Networks 28: 1-23.

Brown, M., Falk, A. and Fehr, E. (2004), "Relational Contracts and the Nature of Market Interactions," Econometrica 72(3): 747-780.

Brown, M. and C. Zehnder (2005), “Credit Registries, Relationship Banking and Loan Repayment,” IEW Working Paper 240, May 2005.

Burger, M. and V. Buskens (2009), "Social context and network formation: An experimental study," Social Networks 31: 63-75.

Burt, R.S. (2005), Brokerage \& Closure. An Introduction to Social Capital. Oxford University Press.

Buskens V. and W. Raub (2010), "Rational Choice Research on Social Dilemmas," in: Wittek, R., T.A.B. Snijders and V. Nee (Eds.) Handbook of Rational Choice Social Research. Russell Sage. New York.

Buskens, V., W. Raub and J. van der Veer (2010), “Trust in Triads: An Experimental Study,” Social Networks 32(1): 301-312.

Callander, S. and C. Plott (2005), "Principles of Network Development and Evolution: An Experimental Study," Journal of Public Economics 89: 1469-1495.

Cassar, A., D. Friedman and P. H. Schneider (2009), “A Laboratory Investigation of Networked Markets,” The Economic Journal 120: 919-943.

Coleman, J.S. (1986), "Social Theory, Social Research, and a Theory of Action," The American Journal of Sociology 91: 1309-1335.

Coleman, J.S. (1988), "Social Capital in the Creation of Human Capital," American Journal of Sociology 94: s95-s120.

Cook, K. S., and R. M. Emerson. (1978), "Power, Equity and Commitment in Exchange Networks," American Sociological Review 43: 721 - 739.

Corbae, D. and J. Duffy 2008. Experiments with Network Formation. Games and Economic Behavior 64:81-120

Corcoran, M., L. Datcher and G.J. Duncan (1980), "Most Workers Find Jobs through Word of Mouth”, Monthly Labour Review, August, pp. 33-35. 
Corten R. and V. Buskens (2010), “Co-evolution of Conventions and Networks,” Social Networks 32: 4-15.

Diekmann, A. and Lindenberg, S. (2001), “Cooperation: Sociological aspects.” International Encyclopedia of the Social and Behavioral Sciences 4: 2751-56. Oxford: Pergamon-Elsevier.

Eguchi, K. (2005), “Job Transfer and Influence Activities,” Journal of Economic Behavior and Organization 562: $187-197$.

Erickson, B.H. (2001), “Good Networks and Good Jobs: The Value of Social Capital to Employers and Employees,” pp. 127-159. In Lin, N., K. Kook and R.S.Burt (Eds.) Social Capital: Theory and Research. Aldine de Gruyter New York.

Falk, A. and J. Heckman (2009), "Lab Experiments Are a major Source of Knowledge in the Social Sciences," Science 326: 535-538.

Falk, A. and M. Kosfeld (2003), “It's all about Connections: Evidence on Network Formation,” IZA Discussion Paper, No. 777.

Fehr, E., G. Kierchsteiger, and A. Riedl (1993), “Does Fairness Prevent Market Clearing? An Experimental Investigation," Quarterly Journal of Economics 108: 437-460.

Fehr, E. and H. Gintis (2007), "Human Motivation and Social Cooperation: Experimental and Analytical Foundations," Annual Review of Sociology 33(3): 1-22.

Fernandez, R., E. Castilla and P. Moore (2000), "Social Capital at Work: Networks and Employment at a Phone Center," American Journal of Sociology 105(5): 1288-1356.

Fernandez, R. and E. Castilla (2001), "How Much is that Network Worth? Social Capital in Employee Referral Networks,” pp. 85-105. In Lin, N., K. Kook and R.S. Burt (Eds.) Social Capital: Theory and Research. Aldine de Gruyter New York.

Fernandez, R. and L. Sosa (2005), “Gendering the Job: Networks and Recruitment at a Call Center," American Journal of Sociology 111(3): 859-904.

Fernandez, R. and I. Fernandez-Mateo (2006), "Networks, Race and Hiring,” American Sociological Review 71(1): 42-71.

Flap. H.D. and E.A.W. Boxman (2001), “Getting Started: The Influence of Social Capital on the Start of the Occupational Career,” pp. 159-185. In Lin, N., K. Kook and R.S. Burt (Eds.) Social Capital: Theory and Research. Aldine de Gruyter New York.

Gintis, H. 2009. "The Unification of the Behavioral Sciences” pp. 242-248. In Gintis, H. (2009) The Bounds of Reason: Game Theory and the Unification of the Behavioral Sciences. Princeton University Press.

Goeree, J., A. Riedl and A. Ule (2008), "In Search of Stars: Network Formation among Heterogeneous Agents," Games and Economic Behavior 67(2): 445-466.

Goldthorpe, J.H. (2000), On Sociology: Numbers, Narratives, and the Integration of Research and Theory, Oxford University Press.

Granovetter, M.S. (1973), The Strength of Weak Ties. American Journal of Sociology 78(6): 1360-1380.

Granovetter, M.S. (1974), Getting a Job: A Study of Contacts and Careers. Basic Books; Cambridge, MA.

Granovetter, M. (1985), “Economic Action and Social Structure: The Problem of Embeddedness,” American Journal of Sociology 91: 481-510.

Holzer, H. (1987), “Search Method Use by Unemployed Youth,” Journal of Labor Economics 6: 1-20.

Karlan, D. M. Mobius, T. Rosenblat and A. Szeidl (2009), “Trust and Social Collateral,” The Quarterly Journal 
of Economics 124(3): 1307-1361.

Kollock, P. (1994), The Emergence of Exchange Structures: An Experimental Study of Uncertainty,

Commitment, and Trust. The American Journal of Sociology, 100(2): 313-345

Lin, N., W.M. Ensel and J.C. Vaughn (1981), "Social Resources and Strength of Ties: Structural Factors in

Occupational Status Attainment," American Sociological Review 46(4): 393-405.

Lin, N. (1999), "Social Networks and Status Attainment,” Annual Review of Sociology 25: 467-487.

Lawler, E.J. and J. Yoon (1996), “Commitment in Exchange Relations: Test of a Theory of Relational

Cohesion," American Sociological Review 61(1): 89-108.

Marsden, P. (2001), “Interpersonal Ties, Social Capital and Employer Staffing Practices,” pp. 105-127. In Lin,

N., K. Kook and R.S. Burt (Eds.) Social capital. Theory and research. New York, Aldine de Gruyter.

Milgrom, P.R. (1988), “Employment Contracts, Influence Activities, and Efficient Organization Design,” The

Journal of Political Economy 96(1): 42-60.

Montgomery, J. (1991), "Social Networks and Labor-Market Outcomes: Toward an Economic Analysis,"

American Economic Review 81(5): 1408-1418.

Parsons, T. (1937), Structure of Social Action, McGraw Hill.

Podolny, J.M. and K.L. Page (1998), “Networks Forms of Organization,” Annual Review of Sociology 24: 57-76.

Raub, W. and J. Weesie (1990), "Reputation and Efficiency in Social Interactions: An Example of Network

Effects," American Journal of Sociology 96: 626-654.

Rees, A. (1966), “Information Networks in Labor Markets,” American Economic Review 56(1-2): 559-566.

Russo, G., C. Gorter and R. Schettkat (2001), “Searching, Hiring and Labor Market Conditions,” Labor Economics 8: 553-71.

Schram, A., J, Brandts and K. Gërxhani (2010), "Information, Bilateral Negotiations,” European Economic Review 54: 1035-1058.

Schram, A. (2005), "Artificiality: The Tension between Internal and External Validity in Economic Experiments," Journal of Economic Methodology 12(2): 225-238.

Seinen I., and A. Schram (2006), "Social Status and Group Norms: Indirect Reciprocity in a Mutual Aid

Experiment," European Economic Review 50: 581-602.

Smith, V. (1962), “An Experimental Study of Competitive Market Behavior,“ Journal of Political Economy 70(2): 111-137.

Streeck, W. (2005), “The Sociology of Labor Markets and Trade Unions,” pp. 254-283. In: Neil J. Smelser and Richard Swedberg (Eds.), The Handbook of Economic Sociology, $2^{\text {nd }}$ Ed., Princeton University Press.

Ule, A., A. Schram, A. Riedl, and T. Cason (2009), "Indirect Punishment and Generosity Towards Strangers," Science 326: 1701-1703, December 182009.

Uzzi, B. (1997), "Social Structure and Competition in Interemployer Networks: The Paradox of Emdeddedness," Administrative Science Quarterly 42(1): 35-67.

Webster, M. and J. Sell (2007), Laboratory Experiments in the Social Sciences. Oxford:Academic Press/Elsevier Western, B. (1998), “Institutions and the Labor Market,” pp. 224-245. In: Brinton, M.C. and V. Nee (Eds.), The New Institutionalism in Sociology. Stanford University Press.

Willer, D. and H. A. Walker (2007), Building Experiments. Testing Social Theory, Stanford University Press. Williamson, O. (1975), Markets and Hierarchies: Analysis and Antitrust Implications. NY: The Free Press. 
Williamson, O. (1985), The Economic Institutions of Capitalism. New York: The Free Press. 


\section{APPENDIX A: EXPERIMENTAL INSTRUCTIONS - TO BE PROVIDED ONLINE}

This appendix gives the English translation of the original Dutch instructions for the sessions with costly information and identification. (Italics indicate places where alternative texts were used for other treatments). The instructions were programmed as html pages. Horizontal lines indicate page separations.

\section{At the start of the experiment:}

\section{Welcome}

You are about to participate in a decision-making experiment. The instructions are simple. If you follow them carefully, you may earn a substantial amount of money. Your earnings will be paid to you in euros at the end of the experiment. This will be done privately, one participant at a time.

The monetary unit in the experiment is 'experimental francs'. At the end of the experiment francs will be converted to euros at a rate of $\mathbf{1}$ euro for $\mathbf{1 5}$ francs.

These instructions consist of 8 pages like this one. During the instructions you can page forward or backward by clicking with your mouse on 'previous page' or 'next page'. Sometimes a page will not fit on your screen. In that case you can use the scroll bar to view the whole page.

\section{Next page}

\section{Rounds and Groups}

The experiment consists of 30 rounds, preceded by 3 practice rounds. After round 10 additional instructions will be given before we proceed.

In every round you will participate in a market where hypothetical goods are traded. Buyers can buy at most one good and sellers can sell at most one good. How you can make money by trading will be explained below.

In total 9 people will participate in the market. There are 4 buyers and 5 sellers. You will have the same role in every round: either buyer or seller. That will be determined before the first practice round. The other buyers and sellers in your market will be the same other participants in every round. You do not know who they are, however. Because there are more sellers than buyers in each round at least one seller will not be able to sell the good.

The composition of markets is anonymous. You do not know with whom you are in the market. Others do not know whether they are with you.

\section{Previous page Next page}

\section{Buying and Selling the Good}

If the buyer buys from a seller s/he pays an agreed upon price. How the price is determined will be explained below.

To deliver the good, the seller may endure costs. There are two possibilities. If the seller delivers a low quality good, there are no costs. If the seller delivers a high quality good the costs are $\mathbf{2 0}$ francs. 
If a buyer gets the good s/he receives a revenue in francs. If the buyer buys a low quality good this revenue is $\mathbf{1 0}$ francs. For a high quality good the revenue for the buyer is $\mathbf{5 0}$ francs.

This allows you to calculate earnings in a round, dependent on the quality.

\section{The good has low quality:}

Earnings for the seller $=$ agreed upon price

Earnings for the buyer $=10-$ agreed upon price

\section{The good has high quality:}

Earnings for the seller $=$ agreed upon price -20

Earnings for the buyer $=50-$ agreed upon price

\section{If you do not buy or sell anything your earnings are 0 .}

\section{$\underline{\text { Previous page }}$ Next page}

\section{Phases}

Each round consists of two phases.

In the first phase of a round buyers and sellers participate in a public market where each buyer can respond to an offer by any seller and vice versa.

In the second phase it is determined whether the good has low or high quality. This is determined by the seller (buyer).

\section{Previous page Next page}

\section{Phase 1}

Participation in the public market proceeds as follows. Buyers may post an offer for the good and this offer holds for every seller in the market. Sellers may post an ask price and this holds for every buyer.

On the lower half of your screen you wil see two rows of boxes. In the top row there is a box for each buyer. In the lower row there is a box for each seller.

You will recognize your own box by its yellow color.

BEWARE: buyers and sellers are randomly reallocated to boxes in every round. Therefore, you cannot keep track across rounds of what specific other participants are doing.

\section{Previous page Next page}

\section{Phase 1}

If a buyer or seller places an offer on the public market, this appears in her or his box.

If you are a seller you will see a button 'accept' next to each buyer's box. By clicking this you indicate that you will sell the good to that buyer at that price. You can only click the button if the buyer concerned is still active on the market. If the buyer has already bought from another seller you can no 
longer click 'accept'. You can still see at what price that buyer bought the good (and you will see the same price in the box of one of the sellers).

If you enter an ask price lower than the highest bid by any buyer, you will automatically sell the good at the price offered by that buyer.

If you are a buyer you will see a button 'accept' next to each seller's box. By clicking this you indicate that you will buy the good from that seller at that price. You can only click the button if the seller concerned is still active on the market. If the seller has already sold to another buyer you can no longer click the button. Again, you will still see the price.

\section{If you enter a bid higher than the lowest ask price by any seller, you will automatically buy the good at the price asked by that seller.}

You may change your bid or ask as often as you like. It does hold that a buyer may only increase the own bid. A seller may only decrease the own ask.

The public market will remain open for 90 seconds. You will see the time count down on your screen. Whoever has not bought or sold when the market closes does not buy or sell the good in that round. When no more sales are possible (4 goods have been sold) the clock automatically jumps down to 5 seconds.

\section{Previous page Next page}

\section{Phase 2}

In phase 2 the seller determines the quality of the good. S/he does this by clicking either 'high' or 'low' and confirming the choice.

As mentioned before: if the quality is low, the revenue for the buyer is 10 and the costs for the seller are 0 . If the quality is high, the revenue for the buyer is 50 and the costs for the seller are 20.

When everyone has finished, the next round starts.

\section{Previous page Next page}

\section{End}

This brings you to the end of these instructions. When everyone is ready we will start the first of three practice rounds. These will not affect your earnings. At the start of the practice rounds we will distribute a summary of the most important parts of these instructions.

When the first practice round starts you will see at the top of your screen whether you are a buyer or seller.

If you have finished reading these instructions, please indicate this by clicking the button 'ready' (at the bottom of this screen). Then please wait quietly until everyone is ready. That may take a little while, so we ask for your patience.

\section{Previous page Back to first page}

\section{Before Round 11:}




\section{An Additional Phase}

We add a third phase to each of the 20 rounds that will follow.

Therefore, from now on each round will consist of three phases. We will first give a brief overview and then provide more details about each phase.

In the first phase each buyer can propose to one seller to negotiate a price for the good separately from the other participants. The seller will be given an opportunity to indicate whether or not $\mathrm{s} / \mathrm{he}$ is willing to negotiate bilaterally. The seller may also decide in phase 1 not to negotiate bilaterally with any buyer (but to only participate in the public market, instead).

In the second phase of a round buyers and sellers negotiate about a price for the good. If a buyer and seller have agreed to participate in bilateral negotiations, they negotiate privately. Any participant not involved in bilateral negotiations participates in a public market like the one in rounds 1-10. Thus, the market is opened at the same time as the private negotiations take place. Those negotiating bilaterally will see what is happening on the public market but cannot participate in it. If the negotiations do not lead to an agreement the buyer and seller concerned can switch and participate in the public market.

No one participating in the public market can observe anything that is occurring in any private negotiations.

In the third phase the quality of the good (low or high) is again determined by the seller (buyer).

Next page

\section{Phase 1}

In phase 1 buyers first indicate whether they want to immediately proceed to the public market or first want to privately negotiate with a seller. This is done using the buttons 'market' and 'negotiate'.

By clicking on 'market' the buyer indicates not wanting any private negotiations.

By clicking on 'negotiate' the buyer indicates a wish to negotiate bilaterally with a seller. Because there are more sellers than buyers, not every seller will be invited to negotiate. A random lottery will be used to determine which seller will be linked to a buyer.

BEWARE: in every round the sellers are randomly allocated to buyers who wish to negotiate. A buyer can therefore not know whether or not $\mathrm{s} / \mathrm{he}$ has previously negotiated with a seller and a seller cannot know whether s/he has previously negotiated with a buyer.

Previous page Next page

\section{Phase 1}

If a seller is offered private negotiations with a buyer $\mathrm{s} / \mathrm{he}$ must indicate whether or not $\mathrm{s} / \mathrm{he}$ is willing to participate in them. This is done by clicking 'yes' or 'no' and confirming the decision.

If a buyer and seller thus agree to negotiate bilaterally the buyer may obtain information about the seller before the negotiations start. We will explain below how this information is collected. 
This information is the number of times that the seller chose low quality and the number of times that the seller chose high quality in previous rounds.

BEWARE: the count of the numbers of low and high quality will start now. No information will be given about choices in rounds that have at this point been finished.

Previous page Next page

\section{Phase 1}

If you are a buyer, the information is collected in the following way.

Before you start negotiating with a seller, you will ask all other buyers about their experiences with this seller. You will not need to ask this yourself. If you are about to negotiate, other buyers are automatically asked for this information.

At the same time, as a buyer you may be asked about your experiences with certain sellers. More specifically, you will be asked to give your experiences with all sellers that are going to negotiate with other buyers. This is done one at a time. When you are asked, we will inform you about your previous experiences with that seller. You will not be asked for information if you have no experiences with a seller.

The information concerned is the number of times that the seller gave you high quality and low quality goods in previous rounds.

There are no costs related to asking for [or providing] information. Giving information costs $\mathbf{0 . 3}$ francs. Therefore, if you give information to all three other buyers in a round, this will cost you 0.9 francs. Of course, if you give no information, you will bear no costs. [last three sentences were dropped in the sessions with costless information]

After all buyers have decided whether or not they want to give information, the information provided is passed on to the buyers who are in negotiations. For each buyer, you will see what information he or she is giving. Buyers have fixed names: "buyer 1", "buyer 2", "buyer 3", and "buyer 4" (if you are a buyer, you will see at the top left of your screen which buyer you are). With these names, you can keep track of which buyers are providing information.

[ In the treatment without identification, the preceding paragraph is replaced by: After all buyers have decided whether or not they want to give information, the information provided is passed on to the buyers who are in negotiations. You will not be able to see which buyers do or do not provide information. Other buyers are denoted by "a buyer", "another buyer", etc. You can therefore not keep track of which buyers are providing information. ] 
Especially in early rounds, it may of course happen that some buyers have no experience with a specific seller. In that case, you will be told that the buyer concerned has no experience with the seller yet.

\section{Previous page Next page}

\section{Phase 1}

In summary, collecting information proceeds as follows.

1. For all sellers involved in negotiations, we will check with which buyers they have traded in previous rounds.

2. as a buyer, you will be asked to provide this information, irrespective of whether you yourself are going to negotiate or buy through the market.

3 . if you as a buyer are asked for information, you choose whether ( 0.3 franks) or not (no costs) you want to provide it.

[alternative for costless provision sessions: if you as a buyer are asked for information, you choose whether or not you want to provide it.]

4. all buyers in negotiations are given the information supplied by others or receive the announcement that another decided not to provide the information.

Note that you will receive no information about your own experiences with the seller. Sellers' identities are anonymous and you can therefore not recognize them from previous rounds.

Beware: the information you receive as a buyer will only appear once. After you have confirmed that you have seen it, the negotiations will start and the information will no longer be shown. If you fear that you may not remember the information, you can write it down. Of course, this will only be useful in the round concerned. In later rounds, you cannot know whether you are dealing with the same seller.

\section{$\underline{\text { Previous page }} \underline{\text { Next page }}$}

\section{Phase 2}

In phase 2 buyers and sellers negotiate the price of the good.

In the market, things proceed precisely as in the first 10 rounds. The only difference is that sometimes not everyone is participating. Recall that those involved in private negotiations are not participating in the market. For these buyers and sellers you will see empty boxes in the market.

Here we explain what happens when buyers and sellers negotiate bilaterally. During these negotiations they can continuously see at the bottom of their screen what is happening in the public market.

The negotiations proceed as follows. After the buyer has seen the information about the seller's previous quality choices the buyer places a bid for the good. This number is entered in the location provided after which the button 'confirm' must be clicked.

Next, the seller must indicate whether or not s/he accepts the bid. This is done by clicking 'yes' or 'no' and confirming. 
If the seller accepts the bid, the buyer and seller must wait until all participants are ready before proceding to phase 3. Participants in the market only notice this by the fact that the corresponding boxes are never activated. Therefore, no one in the market knows the results of private negotiations.

If the seller does not accept the bid, then the buyer and seller can both participate in the public market, if it has not been closed yet. On your screen you will directly enter the market.

\section{Previous page Next page}

\section{Phase 3}

In phase 3 the seller (buyer) determines the quality of the good. S/he does this, just like in the first 10 rounds, by clicking 'high' or 'low' and confirming.

It still holds that a low quality means that the revenue for the buyer is 10 and the costs for the seller are 0 . A high quality means a buyer revenue of 50 and seller costs of 20

When everyone has finished, the next round starts.

\section{Previous page Next page}

\section{End}

This brings you to the end of these instructions. When everyone is ready we will proceed with round 11 of the experiment. We point out once more that we will start counting sellers' quality choices now. This information may be made known to buyers if they bilaterally negotiate with the seller concerned. Whether it is actually made known depends on the willingness of other buyers to provide it.

First, we will distribute a summary of the most important parts of these instructions.

If you have finished these instructions, please indicate this by clicking the button 'ready' (at the bottom of this screen). Then please wait quietly until everyone is ready. That may take a little while, so we ask for your patience.

\section{$\underline{\text { Previous page } \text { Back to first page }}$}




\section{APPENDIX B: INFORMATION PATTERNS - TO BE PROVIDED ONLINE}

In this appendix, we show for each of the nine groups in the treatment with identification and costly information, the patterns of information sharing, as shown for group 1 in table 3 . In addition, we show the 50\%-information connections as described in the main text. In these graphs (on the right) a line connecting two employers indicates that they have $50 \%$ information connection.

\section{Group 1}

\begin{tabular}{|l|c|c|c|c|}
\hline & To A & To B & To C & To D \\
\hline From A & --- & 1.00 & 0.38 & 0.82 \\
\hline From B & 0.73 & --- & 0.86 & 0.43 \\
\hline From C & 0.20 & 0.31 & --- & 0.44 \\
\hline From D & 1.00 & 1.00 & 0.78 & --- \\
\hline
\end{tabular}

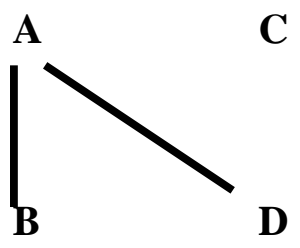

\section{Group 2}

\begin{tabular}{|l|c|c|c|c|}
\hline & To A & To B & To C & To D \\
\hline From A & --- & 0.60 & 0.60 & 0.40 \\
\hline From B & 0.88 & --- & 0.60 & 0.90 \\
\hline From C & 0.42 & 0.28 & --- & 0.36 \\
\hline From D & 0.29 & 0.63 & 0.00 & --- \\
\hline
\end{tabular}

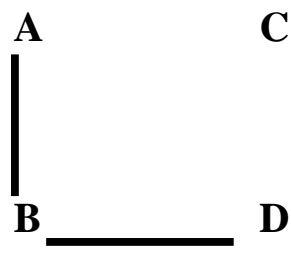

Group 3

\begin{tabular}{|l|c|c|c|c|}
\hline & To A & To B & To C & To D \\
\hline From A & --- & $---*$ & 1.00 & 0.82 \\
\hline From B & 0.50 & --- & 0.67 & 0.27 \\
\hline From C & 0.54 & 1.00 & --- & 0.25 \\
\hline From D & 0.85 & 0.00 & 1.00 & --- \\
\hline
\end{tabular}

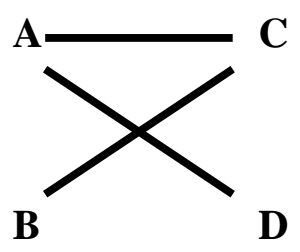

Group 4

\begin{tabular}{|l|c|c|c|c|}
\hline & To A & To B & To C & To D \\
\hline From A & --- & 0.90 & 0.92 & 0.80 \\
\hline From B & 0.71 & --- & 0.82 & 0.20 \\
\hline From C & 0.92 & 1.00 & --- & 0.90 \\
\hline From D & 0.63 & 0.40 & 0.86 & --- \\
\hline
\end{tabular}

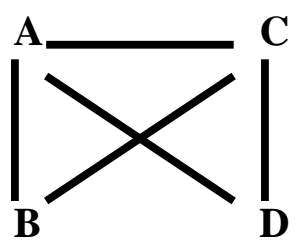

\section{Group 5}

\begin{tabular}{|l|c|c|c|c|}
\hline & To A & To B & To C & To D \\
\hline From A & --- & 1.00 & $---*$ & $---*$ \\
\hline From B & 0.44 & --- & $---*$ & 0.00 \\
\hline From C & 0.50 & $---*$ & --- & 0.00 \\
\hline From D & $---*$ & 0.50 & 0.11 & --- \\
\hline
\end{tabular}
A
C

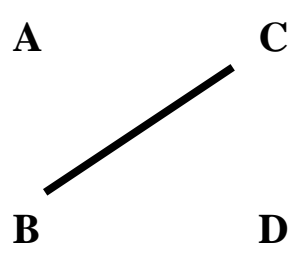

Group 6

\begin{tabular}{|l|c|c|c|c|}
\hline & To A & To B & To C & To D \\
\hline From A & --- & 0.00 & 0.13 & 0.00 \\
\hline From B & $---*$ & --- & 0.75 & 0.00 \\
\hline From C & 1.00 & 1.00 & --- & 0.17 \\
\hline From D & 0.50 & 0.38 & 0.41 & --- \\
\hline
\end{tabular}


Group 7

\begin{tabular}{|l|c|c|c|c|}
\hline & To A & To B & To C & To D \\
\hline From A & --- & $---*$ & $---*$ & 0.00 \\
\hline From B & 0.00 & --- & 0.00 & 0.00 \\
\hline From C & 1.00 & $---*$ & --- & 1.00 \\
\hline From D & 0.33 & 0.00 & 1.00 & --- \\
\hline
\end{tabular}

A

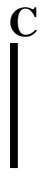

Group 8

\begin{tabular}{|l|c|c|c|c|}
\hline & To A & To B & To C & To D \\
\hline From A & --- & 0.00 & $---*$ & 0.00 \\
\hline From B & $---*$ & --- & 0.00 & 0.00 \\
\hline From C & $---*$ & 0.00 & --- & 0.60 \\
\hline From D & $---*$ & 0.38 & 0.67 & --- \\
\hline
\end{tabular}

A

C

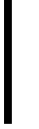

B

D

Group 9

\begin{tabular}{|l|c|c|c|c|}
\hline & To A & To B & To C & To D \\
\hline From A & --- & 0.00 & 0.27 & 0.30 \\
\hline From B & 0.00 & --- & 0.00 & 0.00 \\
\hline From C & 0.00 & $---*$ & --- & 0.00 \\
\hline From D & 0.86 & $---*$ & 0.50 & --- \\
\hline
\end{tabular}

A

C

B D 
TABLES AND FIGURES 
Table 1: Experimental Treatments

\begin{tabular}{|l|c|c|}
\hline & Costless information & Costly information \\
\hline No identification & 6 groups & 6 groups \\
\hline Identification & 5 groups & 9 groups \\
\hline
\end{tabular}


Table 2: Information Sharing per Treatment

\begin{tabular}{|l|c|}
\hline Treatment & Fraction of requests honored \\
\hline No identification, costless & 0.91 \\
\hline No identification, costly & 0.59 \\
\hline Identification, costless & 0.94 \\
\hline Identification, costly & 0.52 \\
\hline
\end{tabular}


Table 3: Example of Information Sharing

\begin{tabular}{|l|c|c|c|c|}
\hline & To A & To B & To C & To D \\
\hline From A & ---- & 1.00 & 0.38 & 0.82 \\
\hline From B & 0.73 & ---- & 0.86 & 0.43 \\
\hline From C & 0.20 & 0.31 & ---- & 0.44 \\
\hline From D & 1.00 & 1.00 & 0.78 & ---- \\
\hline
\end{tabular}
information requests by the employer depicted in the column that is positively responded to by the employer in the row. 
Table 4: Correlation in Information Sharing

\begin{tabular}{|l|c|c|}
\hline \multicolumn{1}{|c|}{ Treatment } & $\begin{array}{c}\text { Correlation } \\
\text { Coefficient }\end{array}$ & Two-sided Significance \\
\hline No identification, costless & -0.20 & 0.233 \\
\hline No identification, costly & 0.31 & 0.068 \\
\hline Identification, costless & 0.13 & 0.527 \\
\hline Identification, costly & 0.56 & $<0.001$ \\
\hline
\end{tabular}

Note. The correlation coefficient measures the correlation between the fractions of (1) information requests by $\mathrm{X}$, honored by $\mathrm{Y}$ and (2) information requests by $\mathrm{Y}$, honored by $\mathrm{X}$. 
Table 5: Employer's Response to Information Request

\begin{tabular}{|l|c|c|}
\hline & Coefficient & Absolute z-value \\
\hline Constant & 1.53 & $3.71^{* *}$ \\
\hline Round & -0.08 & $5.09^{* *}$ \\
\hline Type of channel giver is in & -0.33 & $2.50^{*}$ \\
\hline Most recent decision of requestor $^{2}$ & 0.68 & $5.03^{* *}$ \\
\hline Most recent earning from contract $^{3}$ & 0.01 & $2.10^{*}$ \\
\hline
\end{tabular}

Notes: The table presents the results of a random effects probit regression model where the dependent variable is a dummy indicating whether or not employer $i$ in group $g$ gave information requested by employer $j$ in round $t$. Formally, it gives the estimated maximum likelihood coefficient vector $\beta$ in $\operatorname{Pr}_{t}^{i j g}=\Phi\left(X_{t}^{i j g} \beta+\mu^{g}\right)$ where $\operatorname{Pr}_{t}^{i j g}$ gives the probability that $i$ of $g$ gives information to $j$ in $t$. $\Phi$ denotes the cumulative normal distribution and $X$ is the vector of independent variables described in the first column of the table. $\mu^{g}$ is a (white noise) group-specific error that corrects for the dependencies across individual decision in the same group.

${ }^{1}$ The employer asked for information may be active in the idealized market or in bilateral negotiations. This variable is a dummy equal to 1 in the former case.

${ }^{2}$ The requestor's history in the personal relationship with the employer asked for information is represented by her decision the last time she was asked for information by this same employer.

${ }^{3}$ Earnings (in francs), the most recent time the decision maker traded, no matter in which channel.

$*(* *)$ denotes statistical significance at the 5\% (1\%)-level. 
Table 6: Key Statistics

\begin{tabular}{|c|c|c|c|c|c|}
\hline & & $\begin{array}{c}\text { No- } \\
\text { identification } \\
\& \text { costless }\end{array}$ & $\begin{array}{c}\text { No- } \\
\text { identification } \\
\& \text { costly }\end{array}$ & $\begin{array}{c}\text { Identification } \\
\text { \& costless }\end{array}$ & $\begin{array}{c}\text { Identification } \\
\& \text { costly }\end{array}$ \\
\hline \multirow[t]{2}{*}{$\begin{array}{l}\text { Rows } \\
2-3\end{array}$} & $\begin{array}{l}\% \text { contracts realized } \\
\mathrm{R} 1-10\end{array}$ & 94.2 & 95.4 & 95.5 & 96.1 \\
\hline & $\begin{array}{l}\% \text { contracts realized } \\
\text { R } 11-30\end{array}$ & 95.0 & 95.0 & 95.5 & 92.9 \\
\hline $\begin{array}{l}\text { Row } \\
4 \\
\end{array}$ & $\begin{array}{l}\text { \% contracts in } \mathrm{BN} \\
\mathrm{R} 11-30\end{array}$ & 52.4 & 54.4 & 62.3 & 37.7 \\
\hline \multirow[t]{3}{*}{$\begin{array}{l}\text { Rows } \\
5-7\end{array}$} & $\begin{array}{l}\text { Average wage } \\
\text { (IM) R1-10 }\end{array}$ & 19.20 & 21.83 & 18.90 & 15.09 \\
\hline & $\begin{array}{l}\text { Average wage } \\
\text { IM R11-30 }\end{array}$ & 21.41 & 16.82 & 15.88 & 17.19 \\
\hline & $\begin{array}{l}\text { Average wage } \\
\text { BN R11-30 }\end{array}$ & 32.12 & 31.02 & 32.27 & 29.10 \\
\hline \multirow[t]{3}{*}{$\begin{array}{l}\text { Rows } \\
8-10\end{array}$} & $\begin{array}{l}\text { Fraction high effort } \\
\text { (IM) R1-10 }\end{array}$ & .23 & .34 & .18 & .31 \\
\hline & $\begin{array}{l}\text { Fraction high effort } \\
\text { IM R11-30 }\end{array}$ & .41 & .28 & .26 & .35 \\
\hline & $\begin{array}{l}\text { Fraction high effort } \\
\text { BN R11-30 }\end{array}$ & .67 & .65 & .73 & .66 \\
\hline \multirow[t]{6}{*}{$\begin{array}{l}\text { Rows } \\
11-16\end{array}$} & $\begin{array}{l}\text { Average employer } \\
\text { earnings (IM) R1-10 }\end{array}$ & 0.19 & 1.62 & -1.77 & 2.83 \\
\hline & $\begin{array}{l}\text { Average worker } \\
\text { earnings (IM) R1-10 }\end{array}$ & 14.50 & 15.10 & 15.34 & 13.30 \\
\hline & $\begin{array}{l}\text { Average employer } \\
\text { earnings IM R11-30 }\end{array}$ & 5.18 & 4.33 & 4.6 & 6.72 \\
\hline & $\begin{array}{l}\text { Average worker } \\
\text { earnings IM R11-30 }\end{array}$ & 13.12 & 11.25 & 10.64 & 10.24 \\
\hline & $\begin{array}{l}\text { Average employer } \\
\text { earnings BN R11-30 }\end{array}$ & 4.82 & 5.11 & 6.80 & 7.41 \\
\hline & $\begin{array}{l}\text { Average worker } \\
\text { earnings BN R11-30 }\end{array}$ & 18.65 & 17.95 & 17.74 & 15.84 \\
\hline
\end{tabular}

Notes: R1-10=rounds 1-10 (only centralized market); R11-30=rounds 11-30; IM= Idealized Market; $\mathrm{BN}=$ Bilateral Negotiations (i.e., informal channel). Employer earnings do not take information provision costs into account. These are relatively small and taking them into account does affect any of the conclusions. 
Table 7: Key Statistics per Group

\begin{tabular}{|l|c|c|c|c|c|c|}
\hline Group & $\begin{array}{c}\text { Average } \\
\text { fraction } \\
\text { info given }\end{array}$ & $\begin{array}{c}\% \\
\text { contracts } \\
\text { in BN }\end{array}$ & $\begin{array}{c}\text { Average } \\
\text { earnings } \\
\text { employer } \\
\text { in BN }\end{array}$ & $\begin{array}{c}\text { Average } \\
\text { earnings } \\
\text { worker in } \\
\text { BN }\end{array}$ & $\begin{array}{c}\text { Average } \\
\text { earnings } \\
\text { employer } \\
\text { in IM }\end{array}$ & $\begin{array}{c}\text { Average } \\
\text { earnings } \\
\text { worker in } \\
\text { IM }\end{array}$ \\
\hline 3 & 0.99 & 62.2 & 9.87 & 15.35 & 5.93 & 12.64 \\
\hline 1 & 0.70 & 56.9 & 3.54 & 19.15 & 7.13 & 9.32 \\
\hline 5 & 0.62 & 59.0 & 7.54 & 18.11 & 8.88 & 8 \\
\hline 2 & 0.49 & 50.6 & 6.49 & 14.79 & 6.65 & 6.5 \\
\hline 6 & 0.49 & 50.6 & 1.78 & 19.82 & -3.24 & 21.52 \\
\hline 4 & 0.14 & 47.4 & -0.77 & 21.54 & 1.4 & 11.4 \\
\hline
\end{tabular}

Notes: Data are based on rounds 11-30 only. Groups are identified in first column and ranked by average fraction of information requests responded to positively (second column). IM=Idealized Market; $\mathrm{BN}=$ Bilateral Negotiations (i.e., informal channel). Employer earnings do not take information provision costs into account. 
Table 8: Employer Earnings

\begin{tabular}{|l|c|c|}
\hline Independent variable & $\begin{array}{c}\text { Regression with } \\
50 \% \text {-network } \\
\text { connections }\end{array}$ & $\begin{array}{c}\text { Regression with } \\
80 \% \text {-network } \\
\text { connections }\end{array}$ \\
\hline Constant & $7.15(6.40)^{* *}$ & $6.83(7.72)^{* *}$ \\
\hline BN & $-1.93(1.18)$ & $-0.93(-0.71)$ \\
\hline \# Network connections & $-0.65(0.71)$ & $-0.54(-0.41)$ \\
\hline \# Network connections*BN & $2.55(2.09)^{*}$ & $3.33(1.94)^{*}$ \\
\hline
\end{tabular}

Notes: The table presents the results of a random effects generalized least square regression model where the dependent variable is the employer earnings in the case with costly information and employer identification. Formally, it gives the estimated GLS coefficient vector $\beta$ in $\pi_{t}^{i g}=X_{t}^{i g}$ ' $\beta+\mu^{g}+\varepsilon_{t}^{i g}$ where $\pi_{t}^{i g}$ gives employer $i$ 's earnings in round $\mathrm{t} ; X$ is the vector of independent variables described in the first column of the table; $\mu^{g}$ is a (white noise) group-specific error that corrects for the dependencies across individual decision in the same group and $\varepsilon_{t}^{i g}$ is white noise error. $\mathrm{Z}$-values are in parentheses. $\mathrm{BN}=\mathrm{Bilateral}$ Negotiations (i.e., informal channel).

$*(* *)$ denotes statistical significance at the 5\%(1\%)-level 
Figure 1: Experimental Design

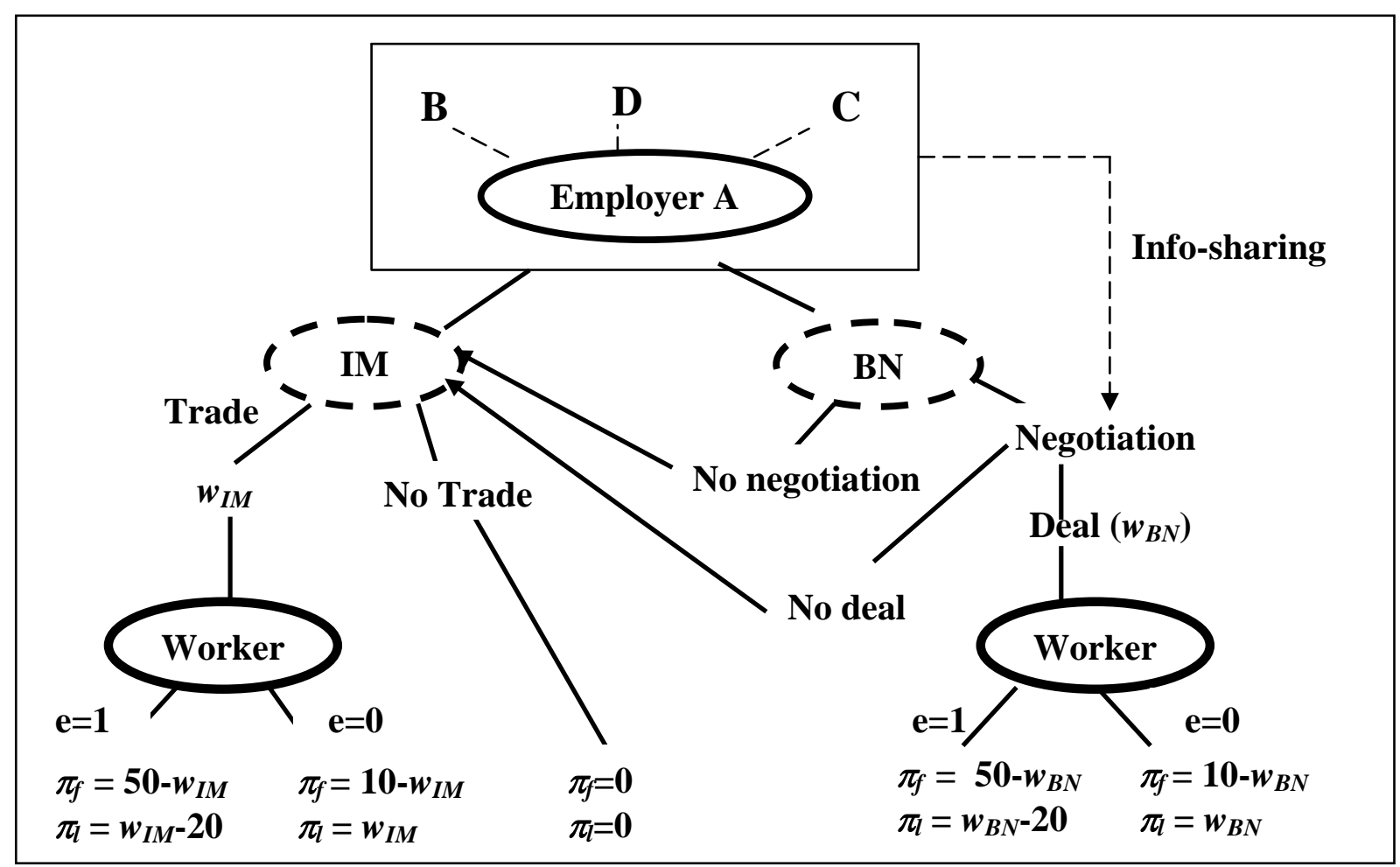

Notes: IM=Idealized market; $\mathrm{BN}=$ Bilateral Negotiations (i.e., informal channel); In $\mathrm{BN}$ the employer first offers bilateral negotiations to one worker. If this is rejected, the employer and worker participate in IM. The same holds if the offer to negotiate is accepted but the wage offer in $\mathrm{BN}$ is rejected by the worker. Before the bilateral negotiations start the employer involved (employer A in this figure) asks other employers (B,C,D) for information about the worker. 